\title{
Reciprocity with the Researcher: An Experimental Manipulation to Increase Help-Seeking in Adults 60 and Older
}

\author{
Elizabeth C. Price
}

Follow this and additional works at: https://researchrepository.wvu.edu/etd

\section{Recommended Citation}

Price, Elizabeth C., "Reciprocity with the Researcher: An Experimental Manipulation to Increase HelpSeeking in Adults 60 and Older" (2015). Graduate Theses, Dissertations, and Problem Reports. 6451. https://researchrepository.wvu.edu/etd/6451

This Dissertation is protected by copyright and/or related rights. It has been brought to you by the The Research Repository @ WVU with permission from the rights-holder(s). You are free to use this Dissertation in any way that is permitted by the copyright and related rights legislation that applies to your use. For other uses you must obtain permission from the rights-holder(s) directly, unless additional rights are indicated by a Creative Commons license in the record and/ or on the work itself. This Dissertation has been accepted for inclusion in WVU Graduate Theses, Dissertations, and Problem Reports collection by an authorized administrator of The Research Repository @ WVU. For more information, please contact researchrepository@mail.wvu.edu. 
Reciprocity with the Researcher: An Experimental Manipulation to Increase Help-Seeking in Adults 60 and Older

\author{
Elizabeth C. Price, M.A. \\ Dissertation submitted to the Eberly College of Arts and Sciences \\ at West Virginia University \\ in partial fulfillment of the requirements \\ for the degree of \\ Doctorate of Philosophy in \\ Psychology \\ Amy Fiske, Ph.D., CBSM, Chair \\ Barry Edelstein, Ph.D. \\ Natalie Shook, Ph.D. \\ Aaron Metzger, Ph.D. \\ Christine Rittenour, Ph.D. \\ Department of Psychology
}

Morgantown, West Virginia

2015

Keywords: Help-seeking, older adults, reciprocity, mental health, masculinity

Copyright 2015 Elizabeth C. Price 


\begin{abstract}
Reciprocity with the Researcher: An Experimental Manipulation to Increase Help-Seeking in Adults 60 and Older

Elizabeth C. Price, M.A.

Seeking help is one way that individuals can maintain and achieve goals, but older adults may be reluctant to ask for help if they feel they cannot give anything in return. Men or individuals who endorse traditional beliefs about masculine behavior may be less likely than other individuals to ask for help. The first aim of the present study was to determine if a brief experimental manipulation based on the norm of reciprocity could increase help-seeking behavior and improve attitudes toward seeking help in older men and women. A second aim was to examine the relation between traditional beliefs about masculine behavior and help-seeking attitudes and behavior. Fifty-six community-dwelling older adults ages 60 to $91(M=68.37, S D=7.30$, $42.86 \%$ male) participated in the current study. To induce reciprocity, participants in the experimental group were given the opportunity to help the researcher; participants in the control group were not. Then, help-seeking behavior was assessed during a difficult puzzle task. There was no significant difference between groups on in-session help-seeking behavior or selfreported attitudes, Wilks' Lambda $(3,42)=0.98, p=.776$. Controlling for age, greater endorsement of beliefs about traditional masculine behavior was associated with poorer attitudes toward seeking help, but not actual help-seeking behavior. Furthermore, the self-report measures of attitudes toward help-seeking were not associated with actual help-seeking behavior. Additional finding regarding age, life-time help-seeking for mental health problems, and depressive symptoms are discussed and provide avenues for future study.
\end{abstract}




\section{Table of Contents}

I. Introduction 1

a. Previous research on help-seeking in older adults 3

b. The norm of reciprocity 9

c. Sex, masculine behavior, help-seeking, and reciprocity 15

d. Statement of the problem 18

e. Specific aims 19

i. Aim $1 \quad 20$

ii. Aim 2

iii. Aim $3 \quad 21$

$\begin{array}{ll}\text { II. Methods } & 21\end{array}$

a. Participants $\quad 21$

b. Materials 21

c. Measures 22

d. Pilot Data 28

e. Procedure 29

i. Training and monitoring of research assistants 29

ii. Recruitment and session procedure $\quad 30$

iii. Analysis plan $\quad 32$

a. Aim $1 \quad 33$

b. Aim 2

c. Aim 3

III. Results $\quad 34$

a. Deception and manipulation check $\quad 34$

b. Task acceptability and participant exclusion $\quad 35$

c. Missing data 36

d. Equivalency of groups $\quad 37$

$\begin{array}{ll}\text { e. Power analysis } & 37\end{array}$

f. Descriptive statistics $\quad 38$

$\begin{array}{ll}\text { g. Bivariate correlations } & 39\end{array}$

h. Assumptions of MANOVA 41

i. Effect of experimental manipulation on help-seeking 41 (Aim 1)

j. Associations among traditional beliefs about masculine behavior 42 sex, and help-seeking (Aim 2)

k. Associations among help-seeking behavior and attitudes 43

(Aim 3)

1. Exploratory analysis

IV. Discussion $\quad 44$

a. Limitations $\quad 55$

b. Summary and future directions $\quad 57$

V. References $\quad 61$

VI. Tables

Table 1. Descriptive statistics for participants demographics by 79 experimental group and sex

Table 2. Descriptive statistics for study variables by group and 81 
participant sex

Table 3. Bivariate correlations among demographic and study variables, full sample $\mathrm{N}=56$.

Table 4. Bivariate correlations among demographic and study variable by experimental group

Table 5. Bivariate correlations among demographic and study variables by sex.

Table 6. Aim 3, Hypothesis 4: Linear regressions predicting

85

in-session help-seeking behavior, controlling for age, sex, and experimental group 
Reciprocity with the Researcher: An Experimental Manipulation to Increase Help-Seeking in Adults Over 60

The number of Americans over age 60 is anticipated to double from the year 2010 to 2050 (Administration on Aging, 2010). Aging brings changes and challenges. Chronic or acute disease and functional impairment are just some of the issues that become more prevalent during late life (Federal Interagency Forum on Aging-Related Statistics, 2012). Nevertheless, individuals are motivated to maximize independence and continue to accomplish goals (Heckhausen, Wrosch, \& Schulz, 2010). Seeking help is one way that individuals can maintain and achieve goals, even with changes in functioning (Haynes, Heckhausen, Chipperfield, Perry, \& Newall, 2009; Heckhausen et al., 2010).

In addition to achieving goals, seeking help in older age is associated with positive affect (Wahl, Becker, Bermandi, \& Shilling, 2004), improved health (Fiori, Consedine, \& Magai, 2008), well-being (Zauszniewski, 1996), and may be particularly important immediately after the onset of disability (Wahl, Schilling, \& Becker, 2007). Seeking help as part of a flexible adaptation to challenges is part of the optimization and compensation process of successful aging (Haynes et al., 2009; Freund \& Baltes, 2002). Help-seeking behavior is not always a welldefined concept in research (Rickwood \& Thomas, 2012). After a comprehensive review of literature on help-seeking for mental health problems, Rickwood \& Thomas (2012) concluded that "help-seeking is an adaptive coping process that is the attempt to obtain external assistance" (p. 180). Seeking help is crucial to obtaining services and treatment for physical and psychological problems, regardless of their relation to aging.

Individuals who need help are often reluctant to seek or accept it (Byers, Area, \& Yaffe, 2012; Moreira, Glasser, \& Gingell, 2005; Saunders, Chisolm, \& Wallhagen, 2012). One reason that older adults may not seek help is because it carries negative connotations. Older adults who 
seek help are more likely to be viewed as dependent than younger people who seek help (AdamsPrice \& Morse, 2009). Meisner (2012) suggests that help-seeking behavior may be avoided because it can prime feelings of dependency, resulting in poorer performance on a range of indices. Older adults who seek help may be viewed as dependent because of the perception that they have little to give in return (Adams-Price \& Morse, 2009). At its extreme, help-seeking may lead to feelings of burdensomeness or the feeling that one is a liability, which has been linked to the desire for suicide (Van Orden, Witte, Gordon, Bender, \& Joiner 2008). On the other hand, rigid independence carries its own risks: a heavy focus on autonomy was found to be related to suicide risk among older adults (Bamonti, Price, \& Fiske, 2013; O’Riley \& Fiske, 2012).

Gender also plays a role in help-seeking behavior and attitudes in late life. The receipt of social support is associated with lower self-esteem and lower positive affect among older men who place a heavy emphasis on independence, but not older women (Nagurney, Reich, \& Newsom, 2004). In a mixed age sample, women were found to perceive helpers and help-seeking behavior in a more positive light than men (Adams-Price \& Morse, 2009). The authors suggest this may be because women are more likely than men to ask for help and to think that giving help is important (Adams-Price \& Morse, 2009).

The focus of the current project is to examine one way to increase help-seeking behavior and improve attitudes about help-seeking in older men and women. This study will use a method to measure in-session help-seeking behavior and examine its relation to attitudinal and self-report measures. First, this proposal will summarize the existing literature regarding help-seeking behavior and attitudes. Interventions that have been used to increase help-seeking behavior or improve attitudes toward help-seeking will be discussed. Then, the norm of reciprocity will be introduced as a factor that may influence help-seeking behavior. The relations among traditional 
beliefs about masculine behavior, the norm of reciprocity, and help-seeking behavior will be discussed. Finally, specific aims will be provided and hypotheses stated, based on the existing evidence.

\section{Previous Research on Help-seeking in Older Adults}

The existing empirical literature largely consists of examinations of help-seeking attitudes and behavior related to psychological or medical problems. Two exceptions are Alea and Cunningham (2003) and studies by Strough and colleagues (2002; 2010), which examined help-seeking attitudes and behavior more generally. Overall, most studies point to low levels of help-seeking behavior for problems common in older adulthood. For example, many older adults with subjective memory problems do not seek help for their memory problems (Hurt, Burns, Brown, \& Barrowclough, 2011). Eighty percent of older adults who reported some type of sexual problem had not sought help for that problem (Moeira et al., 2005). Among older adults with macular degeneration, less than half had sought formal help and fewer than $10 \%$ requested accommodations from those around them (Boerner, Brennan, Horowitz, \& Reinhardt, 2010). In adults over 75 with problems related to fecal incontinence, only $40.8 \%$ had sought help (Stenzelius, Westergren, \& Halberg, 2007). Similarly, only half of community-dwelling people over age 60 with urinary incontinence sought help from a professional (Teunissen \& LagroJanssen, 2004). This is despite the fact that incontinence is usually treatable and that these problems severely impact quality of life (Stenzelius et al., 2007).

Previous research suggests that older adults are unlikely to seek mental health treatment, even among those who meet diagnostic criteria for depressive or anxiety disorders or who are experiencing suicidal thoughts (Byers et al., 2012; Pitman \& Osborn, 2011). Older adults have been found to be more likely to seek help from general practitioners than from specialty mental 
health care providers (as reviewed by Fiske, Wetherell, \& Gatz, 2009; Mackenzie, Gekoski, Knox, 2006). However, Westerhof, Maessen, de Bruijn, and Smets (2008) found that 72.5\% of randomly selected Australian older patients would not talk to any professional about depressive feelings, feelings of anxiety, loneliness, memory complaints, or sleep problems.

Results concerning age differences in attitudes and help-seeking behavior are varied. There are few direct comparisons of older and younger adults. Nadler (1991), a prominent helpseeking researcher, summarized early studies that point to low levels of help-seeking behavior in older adults. In the only experimental examination of help-seeking behavior in older and younger adults, older adults sought little help and were less likely than younger adults to request help on a standard anagram task (Alea \& Cunningham, 2003). Although some studies have found that older individuals report better attitudes toward seeking psychological help than younger people (Berger, Levant, McMillan, Kelleher, \& Sellers, 2005; Mackenzie, Scott, Mather, \& Sareen, 2008), older adults were found to be significantly less likely to have actually sought treatment than younger adults (Robb, Haley, Becker, Polivka, \& Chwa, 2003). However, in a vocational setting, older adults with disabilities were more likely to ask for accommodations than younger adults with disabilities (Baldridge \& Swift, 2013). It seems that age differences vary by the reason for seeking help and whether attitudes or behavior are measured.

In the older adult help-seeking literature, several factors are associated with help-seeking behavior other than simply the severity of the problem (Cornally \& McCarthy, 2010). One consistent and prominent reason for older adults to not seek help is that individuals want to solve problems on their own (Mackenzie, Pagura, \& Sareen, 2010; Milne, 2000; Pepin, Segal, \& Coolidge, 2009; Weinberger, Nelson, \& Roth 2011). Stoicism, or courage in the face of pain and an unwillingness to disclose their pain to others, was found to be inversely related to help- 
seeking for chronic pain among older adults (Cornally \& McCarthy, 2010). On self-report measures of attitudes or willingness to seek help, questions are often worded such that solving problems on one's own is the opposite of seeking professional help (Cohen, 1999; Fischer \& Farina, 1995). This wording emphasizes that older adults who eschew help are choosing to solve problems by themselves.

Stigma may impact help-seeking in several ways. Perceived stigma regarding mental illness, especially internalized stigma that leads the individual to apply negative stereotypes to oneself (Connor et al., 2010), has been found to be associated with lower levels of help-seeking behavior for mental health concerns (Préville et al., 2015). Stigma regarding mental illness may vary by community. African-American older adults were found to be more likely than Caucasian older adults to report internalized stigma related to having a mental illness (Connor et al., 2010).

Stigma related to the behavior of seeking help may also reduce help-seeking behavior among older adults. Much of the research examining stigma regarding seeking help has also been conducted in relation to professional psychological help (e.g., asking participants if they agree with the statement that “...normal people don't go to psychotherapy,” p. 772). Surprisingly, one study found that older adults reported less concern with the with stigma of seeking psychological help than younger adults, but old-old adults (i.e., age $80+$ ), compared to young-old adults, reported significantly more concern (Pepin et al., 2009). Research examining barriers to seeking psychological help indicated that stigma regarding seeking help is not the most prominent reason for not seeking psychological help among younger or older adults (instrumental barriers to seeking help were more important; Pepin et al., 2009).

In the realm of professional services, instrumental factors such as ability to pay and find a therapist or physician are implicated in seeking help from professionals (Pepin et al., 2009; 
Westerhof et al., 2008; Wolinsky \& Johnson, 1991). These may be some of the most important factors associated with the decision to seek help for both younger and older adults (Pepin et al., 2009; Wolinsky \& Johnson, 1991). In the realm of everyday problem solving, spouses are individuals that are typically easily accessed, mitigating these instrumental concerns. Married individuals, compared to non-married individuals, reported greater preference for and use of interpersonal or collaborative problem-solving for everyday problems (Strough, Cheng \& Swenson, 2002; Strough, McFall, \& Schuller, 2010). Collaborative problem-solving may be analogous to help-seeking insofar as the person is choosing to cope with the problem by asking for another's input or allowing someone else to do part of the task (e.g., help them dress in the morning; Strough et al., 2010). The inconvenience or cost of seeking out professionals may lead to low levels of help-seeking behavior for problems that require professional consultation.

Perceptions of need, including comparisons to others and causal attributions, have been shown to predict help-seeking more strongly than objective impairment (Hurt et al., 2011). Older adults who did and did not seek help for subjective memory complaints did not differ in objective impairment, but differed on a range of other factors, such as attributions for the problem and having a relative with dementia (Hurt et al., 2011). In the context of urinary incontinence, perception of the problem varied widely relative to objective impairment but was important in predicting help-seeking behavior (Milne, 2000).

Beliefs about responsibility are also associated with the type of psychological help sought (i.e., professional or informal) and whether or not help is accepted (Hadas \& Midlarsky, 2000). Older adults who believed that they were responsible for creating and solving their problem were more likely to accept psychological treatment than individuals who placed responsibility outside themselves (Hadas \& Midlarsky, 2000). However, another study showed that older people who 
believed that their chronic pain had an organic origin tended to seek more help (Cornally \& McCarthy, 2010).

Related to etiology, individuals' help-seeking behavior was also found to be influenced by beliefs about the ability to effect change (Cornally \& McCarthy, 2010; Hurt et al., 2011; Hadas \& Midlarsky, 2000). Lower self-perceived ability has been found to be associated with a preference for collaborative everyday problem solving among older adults (Strough et al., 2002). In several classic studies of help-seeking behavior, the general construct of self-esteem was found to be related to help-seeking behavior: young people with lower self-esteem sought more help on experimental tasks than young people with high self-esteem (Nadler, 1991). Individuals with higher self-esteem may seek less help because they believe they can solve problems on their own.

Help-seeking may also be dependent on the individual's perception of the relative importance of the problem. Among a sample of depressed older adults, many considered depression to be their least important problem, compared to physical and psychosocial issues (e.g., family problems, loneliness, finances) (Proctor, Masche, Morrow-Howell, Shumway, \& Snell, 2009). This view might explain low levels of help-seeking behavior for depressive symptoms in older adults, who carry a higher physical illness burden.

In summary, factors that influence help-seeking attitudes and behavior in late life include preferences for solving problems alone, stigma about mental illness, stigma about seeking help, instrumental barriers, beliefs about the problem, perceptions of impairment, and perceptions of ability to solve the problem.

Several interventions have been designed to increase help-seeking behavior for physical and psychological problems among older adults. However, neither their design nor their results 
have been impressive. For example, Milne (2000) developed an educational intervention to increase help-seeking behavior for urinary incontinence. Adults over 55 with some level of urinary incontinence were randomly assigned to receive either a pamphlet about urinary incontinence or 1 hour of individualized education about urinary incontinence plus the pamphlet. All information focused on available treatments and the debunking of common inaccurate beliefs (e.g., that incontinence is a normal part of aging). The researchers hypothesized that the extra hour of instruction, in addition to the pamphlet, would increase help-seeking behavior. Fourteen of 45 individuals actually sought help afterwards, but there was no significant difference between groups.

Gulliver, Griffiths, Christensen and Brewer (2012) summarized interventions used to increase help-seeking behavior and improve attitudes about help-seeking for psychological problems. Interventions included education to reduce stigma about mental illness, education about treatments, also known as mental health literacy (in person, by video, e-card/online, or written), and cognitive-behavioral therapy with feedback. These strategies generally improved attitudes towards seeking psychological help but did not increase help-seeking behavior compared to control groups. Only the provision of online cognitive behavioral therapy with personalized feedback resulted in greater self-reported help-seeking behavior from professionals 6 weeks post-intervention, compared to a control group (Christensen, Leach, Barney, Mackinnon, \& Griffiths, 2006). The online CBT program directly encouraged individuals with elevated depression symptomatology to seek empirically-based treatment. This study resulted in a small effect size and the results faded by 6 months post-intervention. None of these interventions were tested in a predominantly older sample, nor was the help-seeking behavior actually observed (Gulliver et al., 2012). 
Considering age, the most relevant study included in the Gulliver et al. (2012) review examined the effect of two educational written materials in a group of "older" individuals (mean age $=44$; Jorm, Griffiths, Christensen, Korten, Parslow, \& Rodgers, 2003). Jorm et al. (2003) hypothesized that information about the efficacy of depression treatment would increase helpseeking behavior. Participants were randomly assigned to receive either a lengthy booklet on efficacious treatments for depression, or a brief, general informational pamphlet about depression. The two groups did not differ in the number of professionals or treatments used in the 6-month follow-up period, although the group that received the longer booklet was able to identify more effective treatments for depression.

Most of the research examining the manipulation of help-seeking behavior has used forms of education or health literacy as the intervention. The literature disproportionately examines self-reported help-seeking attitudes related to seeking help for psychological problems and is lacking in controlled experimental studies. Self-reported help-seeking behavior has been studied (Christensen et al., 2006), but actual, observable help-seeking behavior is missing from these examinations. Furthermore, as reviewed above, there are many factors that may influence help-seeking behavior, including emotional states or beliefs in the receiver, the situation or context, and the individual's perception of the problem (DePaulo \& Fisher, 1980; Nadler, Mayseless, Pen, \& Chemennski, 1985). At the very least, help-seeking is an interpersonal behavior, with the potential for social costs (DePaulo \& Fisher, 1980). Some research examining help-seeking attitudes and behavior has focused on social contexts (e.g., Strough et al., 2002). To date, however, interventions to increase help-seeking behavior have not focused on interpersonal factors.

\section{The Norm of Reciprocity}


Help-seeking behavior can be considered within the framework of the norm of reciprocity. Reciprocity is a strong, internalized moral norm that makes two demands: “(1) people should help those who have helped them, and (2) people should not injure those who have helped them" (Gouldner, 1960, p. 171). Gouldner (1960) wrote that reciprocity is a moral norm that both contributes to cohesion in society and is a way for individuals to ensure benefits, help, and safety in the future. It is self-perpetuating. Reciprocity includes the exchange of goods and services but the specific type, amount, or time frame for repayment may vary based on the characteristics of the individuals involved (Gouldner, 1960). Like homeostasis in the body, reciprocity has been conceptualized as "a goal in itself rather than exclusively as a means to achieve a goal" (Perugini et al., 2003, p. 253). For example, the norm is so strong that individuals will give back even if they are not being observed or the other person might not notice (Burger, Sanchez, Imberi, \& Grande, 2009). Reciprocity is distinct from equity or equity theory, but reciprocity is a part of establishing equity in relationships (Polk, 2011). Reciprocity generally refers to discreet exchanges between individuals. Equity, on the other hand, characterizes whole relationships. In other words, if individuals in a relationship perceive that the norm of reciprocity is being consistently followed, they will be more likely to feel that they have an equitable relationship (Polk, 2011).

The first part of the reciprocity norm (that "people should help those who have helped them") implies that individuals are motivated to contribute after they benefit, and may feel like a burden if they do not (Gouldner, 1960, p. 171). Gouldner stated that "indebtedness" is an important part of maintaining relationships and perhaps the most important feature of reciprocity (p. 174). Indebtedness can be used as a key persuasion and sales tactic. Beginning in the 1970s, the Hare Krishna religious group used this strategy by handing out flowers and books to 
individuals in airports, then requesting donations (Cialdini, 1993). Even a small token, such as a sample of food, can activate the norm of reciprocity and make a return contribution or purchase more likely (Cialdini, 1993). Reciprocity has also been implicated in the "door-in-the-face" technique: the denial of a large request leads to feelings of indebtedness in the potential helper and acquiescence to a later, smaller request (Cialdini et al., 1975).

Experimental studies have shown that individuals adjust their help-seeking behavior to avoid indebtedness. More specifically, young people are more likely to ask for help from another student when they believe that they will be able to help that student on a future task. Greenberg and Shapiro (1971) found that college students were more likely to ask for help on an experimental task if they believed that they would be able to reciprocate to a confederate in the future. Similarly, Nadler et al. (1985) investigated help-seeking behavior, self-esteem, and the expectation of being able to reciprocate help among children. They found that children with high self-esteem asked for more help from another child when they expected that they would be able to reciprocate. The effect was not found in children with low self-esteem, who requested more help than children with high self-esteem regardless of condition.

Opportunities to give and receive may change over the lifespan. Older adults and those with functional disabilities report more over-benefitting, or receiving more than they contribute, compared to younger or non-disabled individuals (Antonucci, Fuhrer, \& Jackson, 1990; Ingersoll-Dayton \& Antonucci, 1988). Over-benefitting can carry negative psychological consequences (McPherson, Wilson, \& Murray, 2010). Receiving support may lead to feelings of being cared for, but also distress related to benefiting in an inequitable way from the relationship (Gleason, Iida, Shrout, \& Bolger, 2008). Among French and American older individuals, both over-benefitting and under-benefitting were associated with reduced life satisfaction compared to 
those who reported that their support relationships were reciprocal (Antonucci et al., 1990; Keyes, 2002). Another study found greater loneliness among older women who perceived either over- or under-benefitting from peers and adult children (Rook, 1987). Previous research indicates that older individuals may rationalize care from their children as being equal to the extensive care they previously provided to their children, termed "deferred reciprocity" (Ingersoll-Dayton \& Antonucci, 1988). But this perception does not extend to professionals or even friends, where reciprocity may be more important (Rook, 1987; Uehara, 1995). Even among mother-daughter dyads, a loss of independence and burdening the caregiver were some of the most commonly cited reasons for discomfort with receiving help (Martini, Grusex, \& Bernardini, 2003).

Both the provision and receipt of emotional support remain high among older adults (Ingersoll-Dayton \& Antonucci, 1988; Keyes, 2002; Li, Fok, \& Fung, 2002), but the receipt of instrumental support or health-related support may be the main source of problematic overbenefitting (Martini et al., 2003). For example, older adults who anticipated receiving more sick care than they provided from their spouse and friends reported substantial negative affect and greater feelings of burden than those who anticipated reciprocal care (Ingersoll-Dayton \& Antonucci, 1988).

Interestingly, Gouldner (1960) concludes that "clearly, the norm of reciprocity cannot apply with full force in relations with children, old people, or with those who are mentally or physically handicapped" (p. 178). This pejorative statement seems to imply that older adults are not able or cannot be expected to contribute and does not take into account the negative effects of over-benefitting. A review of the topic suggests that over-benefitting is the most stressful 
outcome of reciprocity norms and almost always avoided (Uehara, 1995). There is little reason to believe that this norm or its consequences would diminish with age.

Older individuals or those with disabilities, especially those who were previously very capable, may acutely feel the effects of not being able to reciprocate. Individuals may take their own help-seeking and help-giving behaviors as evidence about themselves and their capabilities (Gross, Wallston, \& Piliavin, 1979). Receiving help may infer inferiority, dependency, and inadequacy (Nadler et al., 1985). These qualities are expected to be particularly undesirable in an individualistic culture such as in the United States ${ }^{1}$ (Nadler, 1986). Among individuals with disabilities or those residing in long-term care in the United States, specialized professional help is not easily reciprocated and indicates a loss of status for the recipient (Gross et al., 1979). Experimental research suggests that individuals who are not able to reciprocate help will negatively appraise the helper (Gross et al., 1979; Shumaker \& Jackson, 1979). Negative appraisal could lead to other problems in care-giving situations, such as hostile attitudes, aggression, dissatisfaction in the care recipient, and caregiver stress.

Following the norm of reciprocity, individuals who feel that they are already a burden may not ask for more help. Clients in psychological and medical settings may feel that they are passive recipients of help. Researchers working with individuals with mental illness have suggested that allowing the client to contribute to the therapist or treatment community might make services more appealing (Matejkowski, McCarthy, \& Draine, 2011). Likewise, allowing an older adult to give help may be one way to increase the acceptance of help (both asking for help and improved attitudes toward help-seeking). Nadler et al. (1985) concluded from his

\footnotetext{
${ }^{1}$ Nadler (1986) found that individuals living in a communal culture, an Israeli Kibbutz, sought more help overall, compared to city-dwellers from the same region. Although conclusions cannot be drawn regarding "Western" vs. "Eastern" cultures, this study suggests that communallyfocused living is associated with greater comfort about help-seeking, especially if that helpseeking benefits the group and not just the individual.
} 
experiments that "helping programs" geared towards individuals with high self-esteem should build in a reciprocity component (p. 34). Volunteering could even negate some of the negative effects of over-benefitting: one experimental study found that helping a $3^{\text {rd }}$ party increased liking of a helper and willingness to seek help in the future (Castro, 1974). In other words, volunteering can be part of reciprocity and "giving back" even if the volunteering benefits another group or individual.

In sum, the norm of reciprocity compels individuals to give back when they have received something, but also may result in the uncomfortable state of feeling over-benefitted if giving back is not an option. As their physical functioning declines, older adults may experience the negative impact of over-benefitting especially related to instrumental tasks (Antonucci et al., 1990; Federal Interagency Forum on Aging-Related Statistics, 2012; Martini et al., 2003).

Perceptions of over-benefitting could contribute to the low levels of help-seeking behavior found in older adult populations. Experimental research in young people suggests that individuals will ask for more help if they believe they can give back in the future. However, this concept has not been tested in older adults. In addition, previous experiments have not used a design in which participants actually helped another person, in order to demonstrate change in help-seeking behavior and attitudes.

\section{Sex, Masculine Behavior, Help-seeking, and Reciprocity}

Help-seeking has been identified as a particularly challenging area for older men. Despite the stereotype of men being less likely to ask for help or directions, the empirical support for this proposition is mixed. In some studies, female sex is associated with greater help-seeking behavior (Cornally \& McCarthy, 2010; Teunissen \& Lagro-Janssen, 2003), other studies have found no gender differences (Baldridge \& Swift, 2013; Greenberg \& Shapiro, 1971; 
Zauszniewski, 1996), or even that men have greater health service utilization than women when hospitalization is included, although this may be related to poorer health (Wolinsky \& Johnson, 1991). In a professional setting, high status men (physicians) were less likely to ask for help than lower status individuals (nurses) regarding technology that was new to all staff members (Lee, 2002).

Sex differences in help-seeking behavior may differ based on contextual factors. For example, another study examined the specific reasons that older men and women sought help for urinary incontinence: men's help-seeking behavior was most related to their distress in daily life, whereas women's was most related to objective criteria such as the duration or severity of their symptoms (Teunissen \& Lagro-Janssen, 2003). Pepin et al. (2009) found that older men were relatively more concerned with the stigma of seeking help, whereas older women were more likely to view the instrumental factor of finding a therapist a barrier to seeking psychological help.

Men may be more likely to seek help on tasks that are typically associated with the female role. Strough et al. (2002) found that older men preferred working with another person in the realm of meal preparation, compared to older women, but not in traditionally masculine areas (e.g., home repair). One qualitative study found that older men who cared for their wives sought more outside resources than older female caregivers (Brown \& Chen, 2008). This result can be considered within the context of direct familial care being associated with the female role. Obtaining help for these tasks does not challenge, and may indeed be consistent with, sex-typed behavior.

Nevertheless, men tend to have coping strategies that do not involve seeking help (Chipperfield, Perry, Bailis, Ruthig, \& Loring, 2007; Haynes et al., 2009). Men are less likely 
than women to seek psychological help, especially from specialty mental health care providers such as psychologists (Drapeau, Boyer, \& Lesage, 2009). Older men have been found to seek help for psychological problems at a rate that is about half that of older women (Maercker, Enzler, Grimm, Helfenstein, \& Ehlert, 2005). Although older men may have more positive attitudes about seeking psychological help than middle-aged or college-age individuals, this does not translate into help-seeking behavior (Berger et al., 2005; Mackenzie et al., 2008). In general medical practice, women were found to seek help for general distress or psychosocial problems, whereas men generally were not (Corney, 1990).

Older men may be unlikely to seek help for psychological or aging-related problems because this behavior conflicts with traditional masculine ideologies (Berger et al., 2005; Maercker et al., 2005; Mansfield, Addis, \& Mahalik, 2003). They may have a greater need to assert and maintain their masculinity as their physical health and perception of their own masculinity declines (Calasanti, 2004; Thompson, 2006). In addition to other traditional masculine norms, high value placed on autonomy, or a high need for control, may contribute to lower levels of help-seeking behavior and other problems (Möller-Leimkühler, 2002; O’Riley \& Fiske, 2012). Social costs (loss of independence, competency, and superiority) have been demonstrated to mediate the relation between gender and help-seeking behavior in a sample that included high status men (Lee, 2002). Weinberger et al. (2011), in a letter to the editor of Psychoncology, enumerate reasons why their male patients with prostate cancer did not seek psychological help. Although the men surveyed believed that their doctors would listen and wanted to help them with their emotional problems, 55\% still believed they should be able to handle their problems on their own. 
In the context of psychological disorders, the issue of help-seeking behavior in older men is important because of the high rate of suicide in this group ["women seek help -- men die" (Angst \& Ernst, 1990, as cited by Möller-Leimkühler, 2002)]. As a possible result of delayed help-seeking behavior, men present at intake with a higher illness burden, including more DSMIV Axis I disorders and lower social and adaptive function (Fabrega, Mezzich, Ulrich, Benjamin, 1990). There is evidence to suggest that treatment will work if men seek or accept help and engage in it. Treatments for psychological disorders are effective for older men (Price, Fiske, \& Edelstein, 2014). When older men were targeted for inclusion in research that consisted of participating in treatment, agreement to participate was high (Rosen et al., 1997; Ryberczyk \& Auerbach, 1990). There is little evidence to suggest that older men are more likely to drop out of treatment than older women (Rokke et al., 1999; Thompson, Coon, Gallagher-Thompson, Sommer, \& Koin, 2001; Thompson, Gallagher, \& Breckenridge, 1987). The challenge is to connect older men with care in the first place.

Considering reciprocity and sex, it has been suggested that men are over-benefitted, on average, throughout life (Polk, 2011). Possible outcomes of this over-benefitting include a reluctance to ask for help and that men find themselves less in need of additional help. However, there is little indication that the effect of over-benefitting or the norm of reciprocity differs by sex. McPherson et al. (2010) found that self-perceived burden was not associated with sex. Greenberg and Shapiro (1971) found no sex differences in help-seeking behavior during a task that manipulated the expectation of ability to reciprocate. Recent qualitative research has found that depressed men cited the lack of ability to reciprocate as a main reason for not seeking help (Sierra Hernandez, Han, Oliffe, \& Ogrodniczuk, 2014). Although men may be less likely to ask 
for help in certain situations, there is no evidence that reciprocity operates differently in men and women.

Overall, older men and constructs related to masculinity need to be included in investigations of help-seeking behavior. Previous research has examined gender identity or sex in relation to help-seeking behavior and attitudes. Attitudes toward seeking help or intentions to seek help have been linked with traditional masculine roles or ideologies in mixed age samples (Berger, Addis, Green, Mackowiak, \& Goldberg, 2013; Berger et al., 2005; Nadler, Maler, \& Friedman, 1984; Smith, Tran, \& Thompson, 2008). Actual help-seeking behavior has not. Literature on older men and help-seeking behavior is limited, although there are some relevant qualitative investigations. Traditional beliefs about masculine behavior are beliefs that can be held by men or women. These beliefs include rigid prescriptions about how a man should behave such as "men should not readily share feelings." It is possible that adherence to traditional beliefs about masculine behavior predicts help-seeking behavior in both men and women. The relation between traditional beliefs about masculine behavior and help-seeking behavior in older adult men and women has not been empirically examined.

\section{Statement of the Problem}

Increasing help-seeking behavior among older adults who need help has implications for their health and well-being, as well as for the family members, friends, and professionals who serve them. Although receiving help is associated with positive outcomes, it may also have emotional costs (e.g., Antonucci et al., 1990). Men or individuals who endorse traditional beliefs about masculine behavior may be less likely to ask for help than women or individuals who do not endorse this behavior (Möller-Leimkühler, 2002). In line with the norm of reciprocity, individuals may avoid asking for help if they feel they can give nothing in return (Sierra 
Hernandez et al., 2014). Some writers have suggested that allowing individuals to "give back" in some way to the helper may increase the acceptance of help (Matejkowski et al., 2011).

Experimental studies in younger individuals have shown that the expectation of the ability to reciprocate later is enough to increase help-seeking intentions (e.g. Nadler et al., 1985). Other interventions have successfully targeted attitudes toward seeking psychological help in young people, indicating that these attitudes can be changed (Gulliver et al., 2012). Help from professionals is typically not easily reciprocated. It is unknown if allowing the individual to help an experimenter will have an impact on their subsequent help-seeking behavior or self-reported attitudes towards seeking help.

Likewise, there has been little empirical study of the relation between beliefs about masculine behavior and help-seeking behavior among older men and women. Perhaps endorsement of traditional beliefs about masculine behavior is a better predictor of help-seeking behavior than sex and can help to explain variability in help-seeking behavior within the sexes (Fischer \& Farina, 1995).

Researchers must distinguish between actual help-seeking behavior and attitudes or intentions. Research participants are often inaccurate in their attributions for their own behavior (Nisbett \& Wilson, 1977). Commonly, individuals do not consider contextual factors when verbally reporting on what they might do in a certain situation, which seems applicable to the sensitive and varied nature of situations that call for help-seeking behavior (Nisbett \& Wilson, 1977). Self-reported attitudes toward help-seeking do not necessarily provide information about actual help-seeking. It is unknown if self-reported attitudes about seeking psychological and general help align with actual help-seeking behavior on standardized laboratory tasks. It is also 
unknown if attitudes toward seeking psychological help are a separate construct or related to broader help-seeking behavior across situations (Cohen, 1999; Fischer \& Farina, 1995).

\section{Specific Aims}

The current study attempted to increase help-seeking behavior by capitalizing on the norm of reciprocity. The importance of the current project and previous literature on older adults and help-seeking behavior was derived mostly from the medical and clinical psychology fields. However, the current study used an experimental manipulation with the goals of (1) increasing help-seeking behavior during a puzzle task and (2) improving self-reported attitudes towards help-seeking. Two features of the current study made it more applicable to clinical or professional settings than previous research on reciprocity and help-seeking behavior. First, requiring the participant to ask for help from the researcher, instead of a confederate, more closely approximated seeking help from a professional, especially one associated with psychology or mental health. Second, providing the opportunity for the participants to help first may have made the model more applicable to professional help setting. A professional could initiate a reciprocal exchange early in the relationship in order to facilitate further help-seeking behavior.

Aim 1. The first specific aim was to determine if a brief experimental manipulation based on the norm of reciprocity could increase help-seeking behavior and improve attitudes toward seeking help in older adults. Hypothesis 1 was that participants who were invited to help the experimenter would ask for more help during the puzzle task and report more positive attitudes towards seeking both general and psychological help if they were to need it in the future. Participants in the control group were not given the opportunity to help the experimenter and provided comparison. 
Aim 2. The second aim was to examine the relation between traditional beliefs about masculine behavior and help-seeking attitudes and behavior in older adult men and women, with the understanding that beliefs about masculine behavior are independent from sex or gender identity. Hypothesis 2 was that that greater adherence to traditional beliefs about masculine behavior would be associated with lower levels of help-seeking behavior and attitudes.

Additionally, results were examined to determine if traditional beliefs about masculine behavior, help-seeking attitudes, and in-session help-seeking behavior varied by participant sex. Hypothesis 3 was that male sex, compared to female sex, would be associated with lower levels of help-seeking behavior and poorer attitudes toward help-seeking.

Aim 3. The third aim was to examine the relations among in-session help-seeking behavior and self-report measures of attitudes toward seeking psychological and general help. Hypothesis 4 was that in-session help-seeking behavior and the measures of self-reported attitudes toward seeking help would be significantly associated with one another. Substantial correlations between these variables would serve to validate the self-report measures with actual help-seeking behavior (and visa versa) and/or to indicate if these are similar constructs.

\section{Methods}

\section{Participants}

The final sample consisted of 56 community-dwelling adults age 60 and older. Ages ranged from 60 to $91(M=68.37, S D=7.30$; see means and standard deviations for descriptive statistics in Table 1). Men were targeted for inclusion and $42.86 \%$ of the sample was male. Almost all participants identified as Caucasian. One participant identified as Black or African American, one participant identified as Asian or Pacific Islander, and one female participant did 
not indicate a race. Detailed demographic information regarding marital status, education, occupational status, and size of hometown is presented in Table 1.

\section{Materials}

Tangrams are figures created with 7 standard puzzle pieces: two large triangles, one medium triangle, two small triangles, a square, and a parallelogram. The puzzle pieces used in the current study were plastic, brightly colored, and approximately one to three inches long. The eight puzzles used in the present study were obtained from Read (1965; Appendix A). Tangrams have been used to teach problem-solving and assess creativity in children (Butler, 1994; Domino, 1980). Across a series of studies in children and college students, Domino (1980) found only small correlations between tangram originality and intelligence or academic achievement. A more recent article used tangrams to assess an individual's ability to communicate abstract notions and establish a common vocabulary (i.e., directing another person to solve the puzzle without seeing it; Gupta, Duff, \& Tranel, 2011).

For our purposes, tangrams were chosen because they are difficult but solvable puzzles. The figures used in this study were chosen for variety and difficulty. Difficulty was determined through informal pre-testing. I timed myself attempting different tangram puzzles and categorized them as easy, medium, or hard. I confirmed the categorizations by administering a set of 8 puzzles to 5 graduate students and observing the length of time it took for them to complete each of the puzzles. Based on these observations, the puzzles were ordered from easiest to most difficult. This was done so that individuals who had poorer ability for the task would ask for help on the easier, earlier puzzles and individuals who were more skilled would still encounter very difficult puzzles, providing ample opportunity to ask for help.

\section{Measures}


Positive and Negative Affect Schedule (PANAS; Appendix B). The PANAS is a selfreport scale of various facets of positive and negative affect (Crawford \& Henry, 2004). This scale was used to assess affect immediately after the helping or control portion of the procedure. Items were rated from 1 (very slightly or not at all) to 5 (extremely). The items inquired about current affect. A 10-item version of the PANAS, used in this study, has been validated in old-old adults by Kercher (1992) and in a mixed age sample by Mackinnon et al. (1999). Internal reliability was adequate for positive affect $(\alpha=.78)$ and negative affect $(\alpha=.87)$, and did not vary by age group (Mackinnon et al., 1999). Negative and positive affect were found to be distinct constructs, regardless of age (Mackinnon et al., 1999). In the current study, Cronbach's $\alpha$ was adequate for positive affect, .82 and negative affect, .86 .

Montreal Cognitive Assessment (MoCA; Appendix C). The MoCA is a brief screening tool for cognitive impairment. It was used to characterize the sample and to identify individuals with low cognitive functioning for removal from the sample. The screener includes items measuring executive functioning/visuospatial ability, oral word production, attention, memory, orientation, and abstraction, using common neuropsychological test items (e.g., clock drawing). Scores range from 0 to 30 . A score of 26 or lower has been suggested as the cut-off for cognitive impairment (Nasreddine et al., 2005). The MoCA is superior to the Mini Mental Status Exam in differentiating between individuals with mild cognitive impairment $(M=22.1, S D=3.1)$ and without mild cognitive impairment $(M=27.4, S D=2.2)$ (Nasreddine et al., 2005). In general, it is a sensitive measure, which is why a liberal cut-off of 20 was used in the current study. See MoCA means for study groups in Table 2.

Willingness to Seek Help Scale (WSHS; Appendix D). The WSHS was developed by Cohen (1999). In the current study, it served as a self-report measure of attitudes toward general 
help-seeking. The 25-item self-report scale includes questions that assess recognition of need, self-disclosure, and relinquishing of control, which are thought to be prerequisites to helpseeking (Cohen, 1999). Items reference physical, social, and psychological problems. Items are scored from 0 (do not identify at all) to 3 (identify completely) and scores range from 0 to 75 . The scale showed discriminant validity from a scale of social desirability, which is important because the items are of a sensitive nature (e.g., seeking help if you hit your child; Cohen, 1999). The scale also demonstrated construct validity with a correlation of .78 between scale scores and whether or not the individual had ever sought help for their emotional state or social functioning. Among older adults, lower WSHS scores are associated with negative beliefs about mental illness (Segal et al., 2005).

Chronbach's alpha for the full scale was .85 in the original validation (Cohen, 1999) and .86 in a subsequent study using older adults (Segal, Coolidge, Mincic, \& O’Riley, 2005). In the current study, internal consistency was adequate, $\alpha=.82$.

\section{Attitudes Toward Seeking Professional Psychological Help (ATSPPH; Appendix E).}

This shortened form of the Attitudes Toward Seeking Professional Psychological Help scale was developed by Fischer and Farina (1995). In the current study, this scale was used to measure selfreported attitudes towards seeking psychological help. The 10-item scale is scored from 0 (disagree) to 3 (agree); total scores range from $0-30$. The items are hypothetical in nature. Thus, the scale can be answered whether or not the individual is currently experiencing psychological problems. Construct validity was supported by moderate correlations between individuals' scale scores and whether or not they had sought help for a psychological problem in the past (Fischer \& Farina, 1995). Internal consistency was .84 and test-retest over one month was .80 (Fischer \& 
Farina, 1995). The scale has been used in a mixed-age sample including older adults (Berger et al., 2005). In the current study, Cronbach's $\alpha$ was adequate, .74.

Masculine Role Norms Inventory - Short Form (MRNI-SF; Appendix F). The MRNI-SF is a 21-item measure of traditional beliefs about masculine behavior (Levant, Hall, \& Rankin, 2013). Items are answered on a Likert scale from 1 (strongly disagree) to 7 (strongly agree). Scores range from 21 to 105. It is a shortened version of the Masculine Role Norms Inventory - Revised (MRNI-R), which includes seven subscales: Avoidance of Femininity, Negativity toward Sexual Minorities, Self-reliance through Mechanical Skills, Toughness, Dominance, Importance of Sex, and Restrictive Emotionality (Levant, Rankin, Williams, Hasan, \& Smalley, 2010). The MRNI-SF was created by using the three items with the highest factor loading on each subscale. The MRSNI-SF was evaluated in undergraduate students by Levant et al. (2013). Cronbach's alpha for subscale scores ranged from .79 to .90 for men, and from .75 to .88 for women; alphas for the total scale were .92 for men and .94 for women. A chi-square goodness-of-fit analysis suggested that the 7-factor model operated similarly in men and women.

The MRNI-SF is a newer measure that was chosen for its brevity. Its additional psychometric properties are suggested by studies using the MRNI-R. The MRNI-R has shown discriminant validity via a non-significant $(r=.08)$ relation with the Personal Attributes Questionnaire - Masculinity Scale, which measures self-described masculine or instrumental traits (Levant et al., 2010). However, it shows concurrent validity with three measures that purport to measure endorsement of traditional masculine roles or behavior: the Conformity to Masculine Norms Inventory $(r=.60)$, the Gender Role Conflict Scale $(r=.54)$, and the Normative Male Alexithymia Scale ( $r=.51$; Levant et al., 2010). As an additional indication of construct validity, men scored higher than women on all subscales except for "self-reliance." 
Although most research has been conducted using college students, the MRNI-R has been used in mixed age (Berger et al., 2005) and in an older adult sample after focus group testing (D. Coleman, personal communication, June 3, 2013).

In the current study, internal consistency for the MRNI-SF was adequate, Cronbach's $\alpha=$ .90.

\section{Center for Epidemiologic Studies - Depression Scale (CES-D; Appendix G). The}

CES-D is a 20-item self-report measure used to measure depressive symptoms (Radloff, 1977). Participants are instructed to think about the past week and indicate how often they had experienced these symptoms. Subscales include depressed affect, positive affect, somatic symptoms, and interpersonal symptoms. Items are rated from 0 (rarely or not at all) to 3 (most of the time). Total scores range from 0 to 60. Four items (e.g., "I enjoyed life") are reverse-scored. These positively worded items were included to reflect the idea that depressed individuals have a lack of positive affect, in addition to predominant negative affect (Radloff, 1977). The CES-D was found to have adequate internal consistency, ranging from .84 to .90 (Radloff, 1977). Testretest reliability was also adequate, .67 over 4 weeks (Radloff, 1977). The measure showed sensitivity to detect changes after treatment for depression (Radloff, 1977). The CES-D has been used with older adults and the subscales were each found to have adequate internal consistency in this group (Gatz, Johansson, Pedersen, \& Berg, 1993). In the current study, Cronbach alpha was adequate, .89 .

\section{Optimization of Primary and Secondary Control Scale (OPS) - Compensatory}

Primary Control subscale (Appendix H). The OPS measures how individuals typically approach problems related to achieving goals (Heckhausen, Schulz, \& Wrosh, 1998). It has four subscales. Only the compensatory primary control subscale, which measures self-reported 
propensity to ask for help or try a task a different way, in contrast to trying harder or giving up, was included in the current project. These 8 items are answered on a scale from 1 (never true) to 5 (nearly always true), with higher scores indicating more use of the particular strategy. Total scores range from 8 to 40 . Internal reliability has been found to be adequate for the compensatory primary control subscale ( $\alpha=$.68) (Wahl et al., 2004). In the current study, internal consistency was adequate, $\alpha=.87$.

Four items asking about seeking help. Fiske, Bamonti, Nadorff, Petts, \& Sperry (2013) found that the four items specifically tapping help-seeking within the compensatory primary control subscale showed substantial internal consistency in an older sample, $\alpha=.87$. These four items (e.g., "when difficulties are too great, I ask others for help") provide an additional measure of attitudes toward help-seeking for general problems. In the current study, internal consistency was adequate for the 4 items regarding help-seeking, $\alpha=.80$.

Personal Norm of Reciprocity (PNR; Appendix I). The PNR was developed to measure "reciprocal behavior in the absence of self-interest and social approval" (Matejkowski et al., 2011, p. 203). In other words, the measure consists of items that tap the individual's adherence to the norm of reciprocity. It consists of three subscales: positive reciprocity ("If someone does a favor for me, I am ready to return it"), negative reciprocity (e.g., "if someone is impolite to me, I become impolite"), and belief in reciprocity (e.g., "to help somebody is the best policy to be certain that s/he will help you in the future"; Matejkowski et al., 2011, p. 212). Items are scored 1 (strongly disagree) to 7 (strongly agree). Total scores range from 12 to 84 . Higher scores indicate greater self-reported adherence to the norm. Internal consistency was reported separately for each subscale. Matejkowski et al. (2011) found an adequate Cronbach's alpha for the positive and negative reciprocity subscales, .70 and .75 , respectively. Cronbach's alpha for 
the belief in reciprocity subscale was low, .42 . Consumers of mental health services were found to have significantly higher PNR scores than control participants. The factor structure of the scale was similar in these two groups. Convergent validity was suggested through moderate correlations of the PNR subscales with an older measure of endorsement of reciprocity norms, the Reciprocation Ideology Questionnaire (Matejkowski et al., 2011).

In the current study, internal consistency for the full scale was not adequate, Cronbach's $\alpha=.55$. However, internal consistency for the three subscales varied widely. For the positive reciprocity subscale, Cronbach's alpha was lower than expected, .57 . For the negative reciprocity subscale, Cronbach's alpha was acceptable, .81 . For the belief in reciprocity subscale, Cronbach's alpha was poor, .39 .

Natural Helper Measure (NHM; Appendix J). The NHM was used to measure differences in self-reported propensity to help others (e.g. "I often find myself helping others with their problems"). It is a 5-item scale developed by Stahl and Hill (2008). Items are rated from 1 (never) to 7 (always). Scores range from 5 to 35. Stahl and Hill (2008) found adequate internal consistency, $\alpha=.81$, and that the items loaded onto just one factor in a factor analysis. Test-retest reliability at 2 to 4 weeks was adequate, .67. Among college students, scores on this measure were moderately correlated with intent to pursue a helping career and nurturant, avoidant, and empathic components of three theoretically-derived personality measures (Stahl \& Hill, 2008). Cronbach's alpha in the current study was adequate, .85.

\section{Demographics and history of help-seeking for mental health problems (Appendix}

K). The questionnaire included questions about age, race, sex, marital status, occupational status, and education. Participants also answered two questions regarding lifetime utilization of help for mental health problems or from a mental health care provider. 


\section{Pilot Data}

Pilot testing was conducted to determine the feasibility of the procedure and to gather preliminary data related to the novel tangram task. Pilot testing was conducted with the assistance of 11 older adult participants, five women and six men. These participants were identified through a list of previous research participants. Ages ranged from 65 to $93(M=76.33$, $S D=8.66)$, and thus were older than the main study participants. MoCA scores ranged from 18

to 29. Pilot participants in the experimental group were asked to provide a brief voice recording of a lay psychological reading, ostensibly for a blind student lab member. The bulk of the procedure was determined to be feasible and acceptable to most participants. However, some older adult participants had difficulty reading out loud for the voice recording. In addition, the pilot manipulation was not found to produce differences in in-session help-seeking behavior between groups. The results of pilot testing informed the development of the manipulation used in the current study. Because pilot participants completed a different procedure from the final procedure, they are not included in the main analyses reported below.

Pilot data indicated adequate ranges on the main variables for hypothesis testing. There was a strong negative correlation between traditional beliefs about masculine behavior and insession help-seeking behavior (the number of times help was requested on the tangram task) $(r=$ -.69). There were moderate positive associations between the self-report measures of attitudes toward help-seeking and in-session help-seeking behavior $(r=.48$ for ATSPPH; $r=.34$ for WSHS). There was a large positive correlation between the ATSPPH and WSHS, $r=.80$. Latency to requesting help was weakly associated with all self-report measures (results not reported) but moderately and negatively correlated with the number of times help was requested 
$(r=-.55$; i.e., individuals who asked for less help also tended to wait longer before asking for help the first time).

\section{Procedure}

Training and Monitoring of Research Assistants. I trained three research assistants, one female and two male, to complete the procedure with participants. Including myself, experimenters ranged in age from 21 to 26 years. Training consisted of (1) discussing the importance of random assignment, informed consent, and other components of the procedure(2) observing me complete the procedure with at least two participants (3) practicing the procedure with me, with each other, and at home (approx. 4 hours total) (4) performing the procedure with one to four participants under my direct observation (5) receiving detailed feedback on performance (6) continued individualized coaching on components of the procedure. As part of this training, research assistants demonstrated proficiency in administering a standardized MoCA. I provided the research assistants with guidance and feedback on speaking to older adults in a respectful manner and avoiding ageist statements or behavior. This feedback was based on my 4 years of applied training with older adult psychotherapy clients and research participants, as well as my didactic training in the field of aging. Research assistants were not blind to the goals of the study.

I monitored research assistants throughout the project for adherence to the protocol and observed any session that took place in a participant's home. Each session was also audiorecorded. Audio-recordings were periodically reviewed to confirm recorded data on the tangram task and to monitor research assistants' administration of the protocol, including the MoCA. I scored each MoCA. All written data from the experimental was reviewed, usually with the 
research assistant present to resolve any questions or elements of documentation that were unclear.

Recruitment and Session Procedure. We recruited participants from existing lists of older adult research participants, at senior centers, health fairs, listervs, direct referrals, and via posters in public areas. We contacted potential participants via phone or the participant called and left a message on a secure voicemail. Participants completed a brief screening process over the phone to determine eligibility. Participants were given the choice of coming to the West Virginia University Life Sciences Building or to have the experiment take place in their home. We obtained an address in order to mail a parking pass to the participant or to locate their home.

Participants were randomly assigned to either the experimental or control group by a coin flip occurring immediately before the experimental session. Participants were arbitrarily assigned to a male or female researcher, based on scheduling availability. Upon the participant's arrival to the lab, we followed a standard script. Please see Appendix L for the detailed procedure and script.

First, informed consent and permission to audiotape the session were obtained from the participant.

Participants assigned to the experimental group were asked to give help. We asked them to give advice about where to find and how to recruit older adult research participants. We verbally emphasized that this information was very helpful. We asked individuals randomly assigned to the control group to describe their living room. Participants in both groups were prompted to speak for 60 to 90 seconds.

The PANAS (Appendix B) was administered to assess participants' affect immediately after the manipulation. 
Next, the tangrams were introduced (see Appendix A). Participants were provided with 8 puzzles to solve in 15 minutes. We explained to the participants that they could not move on to the next puzzle without solving the first one, but that they could ask for help. The participants were provided with repeated verbal and written instructions and a "help menu" to indicate the types of help that they could receive (see Appendix L). The help menu was adapted from Alea \& Cunningham (2003). It allowed us to code and provide an appropriate answer for each question in a way that was similar across participants. As a sample item, we demonstrated correctly solving a tangram, mixed up the pieces, and then asked the participant to solve that same tangram. If a participant had difficulty solving the sample task, we showed him or her the correct answer a second time after they had attempted to solve the sample item for about one minute.

The written instructions and help menu were visible throughout the task in large print. The experimenter sat behind and to the side of the participants, out of sight but immediately available to help. The experimenter was allowed to ask participants to clarify the type of help requested, using the help menu, if it was unclear. This allowed for easier and more accurate coding of types of help. Participants occasionally asked procedural questions, such as "do I use all the pieces?" These questions were answered by the experimenter and recorded, but were not counted as help-seeking behavior. After participants completed one puzzle, the experimenter provided the next puzzle. Several standard prompts were given for different scenarios during the task (see Appendix L). The participant was warned when 2 minutes were left for the puzzles. After 15 minutes, the task was discontinued.

Next, the MoCA was administered as an indication of cognitive functioning (Appendix C). Then, the experimenter provided asked the participant to complete the packet of questionnaires (Appendixes D - K). 
After the questionnaires were completed, participants took part in a verbal manipulation check and funnel debriefing. In particular, we asked the participants how much they felt that they had helped the experimenter during either the "recruitment" or "living room" question, on a scale of 1 (didn't help at all) to 5 (helped a lot). The participants were also asked if they believed that they could ask for help on the tangram task. We answered all participant questions. The participant received a 15 dollar gift card and signed the payment receipt. Finally, we asked the participants about their interest in participating in other research or receiving a summary of results.

\section{Analysis Plan}

Descriptive statistics and bivariate correlations among variables were calculated. T-tests and Chi-square analyses were used to screen for sex differences and equivalency of randomized groups.

Aim1. A Multivariate Analysis of Variance (MANOVA) was used to test for differences between the experimental and control groups. The data were examined for the assumptions of MANOVA: univariate and multivariate outliers, linearity, homogeneity of variance-covariance matrixes, and multicolinearity. A MANOVA was chosen because it maximized power to examine multiple outcomes that were moderately correlated (Tabachnick \& Fidell, 2013). The first step in conducting the MANOVA was to examine the correlations between the scales measuring attitudes toward seeking help. Because scores on the ATSPPH and the WSHS were only moderately correlated, they were both retained in the analyses (Tabachnick \& Fidell, 2013).

In-session help-seeking behavior and the scores on the two self-report measures of attitudes toward seeking help served as the dependent variables. Group assignment (experimental or control) was the independent variable. 
Hypothesis 1: A significant omnibus multivariate test (Wilks' lambda) would indicate that the manipulation had the hypothesized effect: more in-session help-seeking behavior and better attitudes towards seeking help in the experimental group, compared to the control group.

Aim 2. Hypothesis 2: For the second aim, three separate linear regressions were used to examine the relation between endorsement of traditional beliefs about masculine behavior and help-seeking behavior and attitudes. Age was controlled for in the regressions because it was significantly correlated with in-session help-seeking behavior.

Hypothesis 3: Additional regressions were conducted using sex to predict help-seeking behavior and attitudes, controlling for age and experimental group.

Aim 3. Hypothesis 4: For the third aim, two linear regressions were used to examine the relations among the self-report measures of help-seeking attitudes and the number of times help was requested. Age was controlled for in the model.

Data cleaning, descriptive analyses, and regression analyses were conducted in SAS 9.3. Checks for the assumptions of MANOVA were conducted in IBM SPSS 18. The MANOVA was conducted in both SAS 9.3 and IBM SPSS 18 and results were identical.

\section{Results}

\section{Deception and Manipulation Check}

Participant responses to questions during the funnel debriefing suggested that the nature of the study was not obvious to the participants. Although some individuals guessed that the procedure was measuring help-seeking behavior or attitudes, none of the participants identified the helping task as being related to the outcome. No individuals identified the nature of the manipulation (e.g., reciprocity or that the question about participant recruitment was related to helping). 
Just before debriefing, all participants except one affirmed that they knew they could ask for help during the tangram task. One participant who said "no" nevertheless asked for help during the tangram task and was included in analyses. Thirty-one percent of the sample spontaneously added verbal comments indicating that they knew they could ask for help but did not want to. Typical comments included, "yeah, but I didn't want to. I wanted to work at it myself" and "yes, you told me I could, but I work puzzles and I didn't like that I couldn’t do it." Participants in both conditions reported similar levels of perceived helpfulness. On a scale of 1 (not helping) to 5 (helping a lot), the mean (SD) score for participants in the experimental group was 3.74 (1.03) and the mean score in the control group was 3.72 (1.51).

\section{Task Acceptability and Participant Exclusion}

To participate in the study, individuals were required to be able to read, see, and use their hands well enough to complete a puzzle. These criteria were established by self-report. All participants attempted the manipulation (i.e., to answer recruitment or living room question). No participant completed all eight tangram puzzles in 15 minutes. All 62 participants worked for the entire 15 minutes on the tangram task and attempted the survey and debriefing interview with adequate effort. Participant frustration was managed by a series of prompts, which were standardized for use across all participants (see Appendix L).

The Montreal Cognitive Assessment (MoCA) was administered to a total of 62 participants. To help ensure that participants could understand and meaningfully participate in the tangram task and questionnaire, I excluded participants from analyses if their score on the MoCA was 19 or below. Five participants scored 19 or below on the MoCA and were excluded, resulting in $N=57$. The excluded participants were three women and two men. Two had been assigned to the experimental group and three had been assigned to the control group. Participants 
removed for low MoCA scores were older than final sample $(M=75.75, S D=9.98$; one participant did not report an age) and all chose to complete the study in their homes. Their average MoCA score was very low, $M=14.00, S D=3.67$.

MoCA scores appeared to be associated with participants' ability to understand the instructions and complete the survey. All individuals who demonstrated inadequate literacy, substantial missing data, or did not understand the tangram task instructions scored below 20 on the MoCA and were removed from analyses. All other participants demonstrated understanding of the task after standardized instructions.

The data were carefully examined for careless responding (e.g., apparent inattention to reverse-scored items, alternating between the first and second answer choices throughout the survey, etc.). No participants were excluded for careless responding. One additional participant was removed for violating the assumptions of MANOVA (see below).

\section{Missing Data}

The data were examined for missing data using frequency counts for each item and careful visual inspection. After the 5 participants who scored below 20 on the MoCA were excluded, there were few missing data. Data appeared to be missing mostly at random. Two participants did not answer one question on the ATSPPH regarding seeking help for sexual problems. Two participants also missed the same item on the PANAS ("alert"). One participant skipped each question that referenced a spouse or children (e.g. "if a serious problem were to arise in my marriage..."). There was no other overlap or obvious patterns of missing data. For most of the self-report measures (i.e., ATSPPH, WSHS, MRNI, OPS, CES-D) 1\% or less of data were missing. On the PANAS, $1.6 \%$ of data were missing. Two participants did not complete the 
Personal Norm of Reciprocity (PNR) scale and the Natural Helper Measure (NHM) because these were added to the questionnaire later.

Missing data were handled in a way that retained the most cases for analyses. If missing data were present, participants' existing item responses for that scale were imputed to produce a prorated scale score. Using this method, no participants were excluded for missing data, with the exception of two participants on analysis involving the PNR or NHM. One participant missed $24 \%$ of items on the WSHS (6 of 25 items). Individual participants' missing data on other scales was $16 \%$ or less per scale. Using a more stringent criterion for missing data, including only cases with $15 \%$ or less of data missing on individual scales, did not change the results of the main analyses.

\section{Equivalency of Groups}

After participants were removed for low MoCA scores, groups were examined to determine the effectiveness of randomization. See Tables 1 and 2 for demographic and study variables by group. Chi square analyses and t-tests were used to determine if groups differed. The experimental and control groups did not differ by age, $t(1,54)=.61, p=.545$, sex of participant, $\chi^{2}(1, N=56)=.02, p=.877$, sex of experimenter, $\chi^{2}(1, N=56)=.02, p=.877$, or location of research, $\chi^{2}(1, N=56)=.01, p=.942$ (WVU vs. home).

Other indicators of pre-existing differences between groups were examined. Groups were similar on MoCA score, $t(1,54)=0.40, p=.691$. Groups did not significantly differ on depressive symptomatology as measured by the CES-D, $t(1,54)=-1.31, p=.194$. Groups did not differ on their adherence to a personal norm of reciprocity $(\mathrm{PNR}), t(1,52)=.19, p=.849$ or on the Natural Helper Measure, $t(1,52)=-0.87, p=.364$. Groups also did not differ on their PANAS positive, $t(1,54)=0.63, p=.533$, or PANAS negative, $t(1,54)=1.02, p=.314$, 
subscale scores. This suggests that the question about where to recruit participants (experimental group) and the question about the participant's living room (control group) did not differentially impact affect.

\section{Power Analysis}

G*Power calculates that for a MANVOA with two groups (one predictor variable) and three outcome variables, a sample size of 48 provides $80 \%$ power to detect a medium-size effect (Faul, Erdfelder, Lang, \& Buchner, 2007). The current sample includes 56 participants, suggesting adequate power. The current sample size is also consistent with a cell size of 20, considered adequate to satisfy the requirements of MANOVA (Tabachnick \& Fidell, 2013).

\section{Descriptive Statistics}

Means for study variables for the overall sample, by group, and by participant sex are displayed in Table 2. Although means for latency to seeking help appeared to differ between groups, this difference was not significant, $t(1,54)=1.32, p=.192$. Using t-tests for each study variable, there were no significant differences between the experimental and control groups.

Chi-square analyses and t-tests were used to examine sex differences in demographic characteristics (Table 1). There were no significant sex differences on age, race, marital status, education, occupational status, or size of hometown.

T-tests were used as preliminary indications of differences between male and female participants on the study variables. Male and female participants did not vary by number of times help was requested, $t(1,54)=-0.79, p=.432$, or latency to requesting help, $t(1,54)=0.49, p=$ .627. However, female participants solved more puzzles than male participants, $\mathrm{t}(1,54)=-.2 .14$, $p=.037$, even though there was no significant sex difference in MoCA scores, $t(1,54)=-1.79$, $p=.096$. Male participants had significantly higher scores on the MRNI-SF, $t(1,54)=2.14, p=$ 
.036. Male and female participants did not significantly differ on any other study variable (see Table 2).

Means were examined by whether participants were run by male researchers or female researchers. These two groups did not significantly differ in the number of times they requested help during the tangram task, $t(1,54)=-1.22, p=.23$. Means on the ATSPPH and WSHS were similar between female-run and male-run participants. Mean scores on the MRNI were higher for participants run by male researchers $(M=66.58, S D=15.35)$ than participants run by female researchers $(M=62.25, S D=14.90)$, but this difference was not statistically significant.

During the tangram task, the most frequently requested type of help was "Type 3" or a "check" (see help menu in Appendix L). Over 55\% of participants requested this type of help, which required simply a "yes" or "no" from the experimenter. Over $37 \%$ of participants requested the position of one piece in the puzzle, $19.64 \%$ requested the position of two pieces in the puzzles, and $28.57 \%$ asked for the solution to at least one of the puzzles. Nine participants ( $16.07 \%$ of the total sample, six in the control group and three in the experimental group) did not request any help. Twenty-four percent of participants in the control group and $25.81 \%$ of participants in the experimental group asked for help 2 or fewer times during the tangram task.

\section{Bivariate Correlations}

Correlations are presented for the full sample in Table 3. Older age was moderately correlated with lower MoCA scores, fewer tangram puzzles solved, less in-session help-seeking behavior, and longer latencies to asking for help. The number of tangram puzzles solved was also moderately and positively related to MoCA score.

The ATSPPH and WSHS were moderately and positively correlated, but neither of these measures was significantly correlated with in-session help-seeking behavior. Latency to seeking 
help was strongly correlated with the number of times help was requested on the tangram task, but this relation was partially driven by the nine participants who did not request any help (latency to seeking help was scored as 900 seconds, the entire 15 minutes). When only participants who requested help were included, the correlation in the full sample dropped from $r$ $=-.69$ to $r=-.49$.

Endorsement of traditional beliefs about masculine behavior (MRNI-SF) shared a moderate negative correlation with both the ATSPPH and the WSHS. In other words, individuals with greater endorsement of traditional beliefs about masculine behavior reported more negative attitudes about help-seeking.

The Personal Norm of Reciprocity (PNR) scale showed a moderate positive correlation with the MRNI-SF and a moderate negative correlation with the WSHS. Because the three PNR subscales differed widely in their internal consistency, correlations were also run separately for each subscale. The correlations between the MRNI-SF, WSHS, and the negative reciprocity subscale of the PNR, which had the strongest internal consistency, were similar to the correlations with the total PNR listed in Table 3. Correlations between the two other PNR subscales and other study variables were small and non-significant.

How helpful the participant felt, as reported during the debriefing, showed small to moderate correlations with MoCA score, the number of tangram puzzles solved, the WSHS, and the OPS subscale. Individuals who had higher MoCA scores and those who solved more puzzles reported feeling less helpful. Feeling more helpful was associated with higher WSHS and OPS subscale scores. 
The four items on the OPS subscale that represented propensity to seek help showed similar correlations to other study variables as the full OPS compensatory primary control subscale.

Some differences in the pattern of correlations can be observed between experimental groups (Table 4) and between men and women (Table 5). There were moderate correlations between CES-D scores and perceived helpfulness which were negative for the control group and positive for the experimental group. The relation between the CES-D and OPS subscale was large and negative for male participants, but very small for female participants. Interpretation of these statistics should be made with caution because of the smaller sample sizes. Many moderately sized correlations are non-significant because of the sample size.

\section{Assumptions of MANOVA}

The data were examined to determine if the assumptions for MANOVA were fulfilled. The variable representing in-session help-seeking behavior was slightly skewed and kurtotic (above absolute value of 1.0). Relative to the full sample, there was one univariate outlier on this variable, indicated by a z-score of above an absolute value of 3.2, a participant who asked for help 10 times. This participant was female and had been randomized to the control group.

Based on visual inspection of scatter plots, there were no curvilinear relations between variables. Variables were roughly homoscedatic, although this was difficult to assess because of low correlations. There were no multivariate outliers (as measured by Mahalonobis' distance, $\alpha<$ $.001)$. Multicollinearity was not a problem because most variables shared very low $(<.10)$ to moderate (.50) correlations. Variances were examined in each cell (dependent variable by group). Variances for individual variables were within the guideline of 10:1 (Tabachnick \& Fidell, 2013). Levene's test was not significant for any of the three dependent variables. Box's M 
was significant $(14.16, \mathrm{p}=.039)$, indicating potential problems with the variance-covariance matrix. After the single participant violating univariate normality was removed, Box's M became non-significant and skew and kurtosis on the tangram help variable decreased to below 1 . After this participant was removed from analyses, final $N=56$. Exclusion of this participant did not change the main study results.

\section{Effect of Experimental Manipulation on Help-Seeking (Aim 1)}

In order to test whether the experimental manipulation was associated with in-session help-seeking and help-seeking attitudes (H:1), I conducted a between-subjects 2 (experimental X control) by 3 (in session help-seeking, ATSPPH, and WSHS) MANOVA. There was no significant multivariate effect, Wilks' Lambda $(3,42)=0.98, p=.776$.

Because of the apparent differences in mean latency to seek help between groups, I conducted an exploratory analysis using a 2 (experimental group) X 3 (ATSPPH, WSHS, latency to seeking help) MANOVA. The multivariate effect was not significant, Wilks' Lambda $(3,52)$ $=0.95, p=.438$.

\section{Associations among Traditional Beliefs about Masculine Behavior, Sex, and Help-Seeking}

\section{(Aim 2)}

I used three separate linear regressions to examine the relations among traditional beliefs about masculine behavior, help-seeking behavior, and attitudes, controlling for age, (H:2). Traditional beliefs about masculine behavior, as measured by the MRNI-SF, significantly predicted attitudes toward seeking professional psychological help $(\mathrm{ATSPPH}), \mathrm{B}=-0.92(\mathrm{SE}=$ $0.40), \mathrm{t}(51)=-2.28, p=.027$. The MRNI-SF was also significantly associated with the WSHS, $\mathrm{B}=-0.94(\mathrm{SE}=0.27), \mathrm{t}(51)=-3.49, p=.001$. The MRNI-SF did not predict in-session helpseeking behavior, $\mathrm{B}=-1.04(\mathrm{SE}=1.09), \mathrm{t}(51)=-0.95, p=.462$. 
I used regressions to examine the impact of participant sex on the main study variables, controlling for age (H:3). Male participants had significantly higher scores on the MRNI-SF, compared to female participants, $\mathrm{B}=-0.01(\mathrm{SE}=0.00), t(52)=-2.18, p=.033$. However, participant sex did not predict ATSPPH, $\mathrm{B}=0.01(\mathrm{SE}=0.01), t(52)=0.67, p=.508$, or WSHS scores, $\mathrm{B}=0.01(\mathrm{SE}=0.01), t(52)=0.70, p=.486$. Participant sex was also not associated with in-session help-seeking behavior, $\mathrm{B}=0.03(\mathrm{SE}=0.04), t(52)=0.86, p=.391$.

\section{Associations among Help-Seeking Behavior and Attitudes (Aim 3)}

Aim three was to assess the relations among in-session help-seeking behavior, attitudes toward seeking professional psychological help, and general help-seeking attitudes (H:4). I used two regressions and controlled for age in each analysis. In-session help-seeking behavior was not associated with ATSPPH, $\mathrm{B}=0.02(\mathrm{SE}=0.05), t(52)=.0 .47, p=.638$, or WSHS B $=0.01(\mathrm{SE}$ $=0.04), t(52)=.0 .20, p=.840$.

\section{Exploratory Analyses}

To attempt to capture the effect of feeling helpful (which might activate reciprocity regardless of group assignment), I conducted an exploratory linear regression to examine the relation between perceived helpfulness and the number of times help was requested on the tangram task across groups. In addition to age, CES-D scores were controlled for in the regression because of their moderate correlation with perceived helpfulness (see Table 4). Perceived helpfulness was not associated with in-session help-seeking behavior, $\mathrm{B}=0.12$, $\mathrm{SE}=$ $0.21, t(51)=0.57, p=.572$.

To further probe the relation between latency to seeking help and experimental group, I conducted an ANOVA to examine latency by group assignment, controlling for age. The effect of group on latency was not significant, $F(3,52)=1.37, p=.248$. I re-ran this analysis using 
only those individuals who had asked for help (i.e., latency did not equal 900 seconds). The effect of group assignment on latency was once again not significant, $F(3,43)=0.02, p=.900$. Just over $64 \%$ of participants reported that they had sought help from a mental health professional in their lifetime. Whether or not participants had sought help from a mental health professional was not related to whether or not they sought help during the tangram task, Chi square $(1, N=56)=.36, p=.55$ or the number of times help was requested, controlling for age, $\mathrm{B}=0.32, \mathrm{SE}=0.53, t(51)=0.60, p=.551$. However, scores on the WSHS and ATSPPH were significantly associated with whether or not a participant had sought help from a mental health care professional in their lifetime, $\mathrm{B}=4.00, \mathrm{SE}=1.86, t(51)=2.15, p=.036$ for the WSHS; $\mathrm{B}=$ 4.60, $\mathrm{SE}=1.21, t(51)=3.80, p=.001$ for the ATSPPH.

Participants were also asked if they had sought help for a mental health problem from any other professional (e.g., nurse, regular doctor, or clergy); $60.71 \%$ of participants reported that they had sought help for a mental health problem from one of these sources. Individuals who had sought help for a mental health problem had higher mean scores on the WSHS and ATSPPH than those who did not. However, none of the three indices of help-seeking or help-seeking attitudes were significantly associated with seeking help from another professional. For the number of times help was requested, $\mathrm{B}=0.06, \mathrm{SE}=.54, t(51)=0.11, p=.909$. For WSHS, $\mathrm{B}=$ $1.95, \mathrm{SE}=1.88, t(51)=1.04, p=.304$. For $\mathrm{ATSPPH}, \mathrm{B}=2.33, \mathrm{SE}=1.30, t(51)=1.79, p=$ .079 .

\section{Discussion}

The main purpose of this project was to test a manipulation of help-seeking behavior and attitudes among older adults. I attempted to manipulate reciprocity by inviting one group of participants to help the experimenter during the experimental task, to see if this would increase 
subsequent help-seeking behavior or attitudes, compared to a group that did not have the opportunity to help the experimenter. Although I was not able to find support for this hypothesis, there were significant relations among help-seeking attitudes and a measure of traditional beliefs about masculine behavior. Other interesting findings concerning help-seeking attitudes, age, and lifetime help-seeking for mental health problems were identified.

Aim 1 was to examine if the norm of reciprocity could be used to increase help-seeking behavior and improve help-seeking attitudes among older adults. Participants given the opportunity to help the experimenter were expected to ask for more help during a standardized puzzle task and to report better attitudes toward seeking help than participants in the control group. This hypothesis could not be supported by the current study, at least partially because the two groups did not differ in how helpful they felt they were being to the experimenter. There were no differences in measures of in-session help-seeking behavior or attitudes between the experimental and control groups. Thus, the current study could not replicate previous studies of reciprocity and help-seeking behavior in younger people (Greenberg \& Shapiro, 1971; Nadler, 1987).

One explanation for why the hypothesized result was not found was a lack of differential effect of the experimental task, compared to the control task. All participants answered one question at the end of the experimental session regarding how helpful they felt that they had been during the question about their living room (control) or recruiting more participants (experimental). Participants in both the experimental and control conditions reported similar levels of perceived helpfulness. 
Choice of experimental and control tasks was limited by several factors. First, the task had to be portable so that it could be performed in the lab and in a participant's home in the same fashion. Second, the task had to be simple enough that all participants could attempt it, regardless of physical dexterity. Previous research examining help-seeking behavior has used tasks such as pickup up papers dropped on the floor or constructing complex paper boxes (Greenberg \& Shapiro, 1971; Levin \& Isen, 1975; Shumaker \& Jackson, 1979). I was concerned that choosing a task that required flexibility, balance, strength, or a high level of digital dexterity would disadvantage certain older adults. Third, the two tasks had to be roughly equivalent, standardized, relevant, and believable to participants. Forth, in order to set up reciprocity, help given by the participant had to clearly benefit the experimenter. Within these parameters, asking about the participant's living room and asking about where the experimenter might find additional older adult research participants seemed to be good options. When we asked what participants thought the "living room" question was about, many participants stated that they thought we were testing their memory. The unanticipated result was that participants who answered the "living room" question believed that it was an important part of the procedure, and thus believed that they were helping us.

One overall challenge to studying reciprocity and help-seeking behavior is that participants who agree to take part in a research study are likely to already feel that they are being helpful. It is worth noting that many participants spontaneously expressed both enjoyment of completing psychological research and the desire to help young researchers. Although I am pleased that so many older adult participants reported enjoying research, their enthusiasm makes the study of reciprocity and help-seeking behavior more difficult. Any manipulation must increase feelings of help-giving or helpfulness above and beyond what participants feel they are 
already doing. Alternatively, previous research has used confederates: participants believed they were receiving help from and giving help to another "participant" (Greenberg \& Shapiro, 1971; Nadler, 1987). This reduced the likelihood that the participant would feel that he or she had already helped that person. I used a different procedure to attempt to test how seeking help from a professional (e.g., psychologist) might possibly be influenced by reciprocity. However, the use of confederates in future studies might ameliorate the problem of participants already feeling helpful.

Aim 2 was to examine the relation between adherence to traditional beliefs about masculine behavior and help-seeking behavior and attitudes. Across experimental groups, participants with higher levels of adherence to traditional beliefs about masculine behavior were expected to seek less help and report poorer attitudes toward seek help. This hypothesis was partially supported. Controlling for age, adherence to traditional beliefs about masculine behavior was significantly related to the measures of attitudes (ATSPPH and WSHS) but not insession help-seeking behavior.

The current results are consistent with past work in younger and middle adults and extend these findings to older adults. Recent research on masculinity and help-seeking has continued to examine behavior and attitudes among young and middle-aged men (Berger et al., 2013; Hammer, Vogel, Heimerdinger-Edwards, 2013). Typically, older adults have not been included in this research, making the current results a unique contribution to the literature. Behavioral observations or in-session measures of help-seeking behavior have also not been previously examined in relation to traditional beliefs about masculine behavior. 
The results of the present study suggest that sex alone is not significantly associated with differences in help-seeking attitudes among older adults. The current finding is also in line with gender researchers' call for the inclusion of women in research examining masculinity and mental health (Magovcevic \& Addis, 2008). Although men in the current study scored significantly higher than women on endorsement of traditional beliefs related to masculine behavior, men and women did not differ in the number of times they sought help during the tangram task. Men and women's attitudes toward seeking help were also not significantly different. This finding is in contrast to common lore and empirical data such as that reported by Drapeau et al. (2009) and Mackenzie et al. (2006). One recent study of Mexican older adults found that men were actually more likely than women to seek help for depression (Perez-Zepeda et al., 2014). The authors suggest that men's higher status in this culture leads to a promotion of their health over women's. Men may typically have more resources to seek help, compared to women. Endorsement of traditional beliefs about masculine behavior is a predictor of helpseeking attitudes for both men and women. The implication is that traditional beliefs may reduce help-seeking behavior in both sexes.

Aim three was to validate the in-session measure of help-seeking behavior with the selfreport measures, controlling for experimental group. The ATSPPH and WSHS were associated with each other, but not with in-session help-seeking behavior on the tangram task. Attitudes toward seeking help for psychological problems, as measured by the ATSPPHS, showed the same pattern of correlations as attitudes toward seeking help for more general interpersonal and physical challenges (WSHS). These measures also shared a moderate correlation, suggesting that self-reported attitudes about seeking help may be relatively stable across domains or type of help needed. 
However, the lack of relation between in-session help-seeking behavior and the selfreport measures of attitudes towards help-seeking suggests several possibilities: the in-session help-seeking task may not have been reliable or valid, the self-report measures may not be valid, or the in-session and self-report measures may be measuring different constructs.

The tangram task may not have been a reliable or valid measure of help-seeking behavior. It was a novel measure designed for the current study and had not been previously used for hypothesis testing. Reliability can be demonstrated through calculated test-retest or inter-rater reliability, or by administering the test to different samples. These were not performed as part of the current study. Face validity was suggested by the parameters of the task and careful administration: participants had to verbally ask for help from the experimenter in order to receive help. Because of the complexity of the procedure and the use of multiple research assistants, it is possible that there were subtle variations in administration that obscured the results. However, the use of random assignment, a script, and training and monitoring of research assistants, should have improved reliability of the behavioral task. The self-report measures (WSHS and ATSPPH) have shown good internal consistency and other psychometric properties suggesting reliability (Cohen, 1999; Fischer \& Farina, 1995). The fact that they shared a moderate correlation and have shown in this and past research to be related to self-reported lifetime history of helpseeking for mental health problems suggests validity (Cohen, 1999; Fischer \& Farina, 1995).

More likely, the in-session and self-report measures of help-seeking were measuring different constructs or facets of help-seeking. These variables differed in response type (verbal vs. written), response options (requesting a certain type of help vs. rating on a Likert-type scale), whether or not interaction with the experimenter was required, whether behavior or attitudes were being measured, and content of item (puzzles vs. hypothetical psychological, interpersonal, 
and physical dilemmas). Future studies could match the content of the self-report items and observational items more closely (e.g., to both be about puzzles, or both be about mental health). Previous interventions aimed at increasing help-seeking behavior have demonstrated changes in attitudes but not behavior (Gulliver et al., 2012). Earlier research suggests that attitudes only predict behavioral intentions when attitudes towards the specific act, normative beliefs, and the individual's motivation to comply with those norms are included in the prediction model (Ajzen \& Fishbein, 1973). The current project did not assess perceived norms related to help-seeking, so it may not be surprising that attitudes and behaviors were not associated. Overall, observational or behavioral measures are generally more reliable than self-report measures and considered the "gold standard" of assessment (Haynes \& O’Brien, 2000). Moreover, behavior is more important than attitudes when considering the function of help-seeking (i.e., to actually obtain assistance). The current findings highlight the need for future studies to employ observational measures in addition to self-report measures assessing attitudes and norms when studying help-seeking behavior.

This study resulted in several other interesting findings. Older age was associated with less help-seeking behavior and greater latency to seeking help (median age of participants was 66; see Table 3). Older age was also significantly correlated with lower MoCA scores and fewer puzzles solved. To briefly illustrate age differences, participants were examined by whether they were in the young-old $(60-69)$ or middle- to old-old $(70+)$ age groups. The current study included 10 participants aged 70 to 78 and 6 participants aged 80 to 91 . Compared to participants under 70, participants 70 and over had significantly lower MoCA scores, 24.43 vs. 26.45, $t$ (1, $54)=2.60, p=.012$. Participants 70 and older asked for help about 2 times on average, compared to nearly 3 in the under-70 group. Most tellingly, $31.25 \%$ of participants over $70 \mathrm{did}$ 
not ask for any help on the tangram task, compared to just $10 \%$ of participants under 70 . Participants age 70 and older solved significantly fewer puzzle correctly, compared to the younger group, 1.25 vs. $2.15, t(1,54)=2.60, p=.012$.

Older participants had lower MoCA scores and solved fewer puzzles, but asked for less help. One explanation could be that help-seeking behavior is a complex skill: effective helpseeking may require higher-level cognitive skills. On the other hand, because the tangram task appeared to be a test of problem-solving skill and quickness, older adults who perceive that their cognitive skills have declined because of age may be especially reluctant to ask for help (Elias \& Lowton, 2014; Hurt et al., 2011).

Cohort and age differences in late life help-seeking are supported by previous studies. By comparing nationally representative samples of individuals over 50, Sacco, Kuerbis, Goge, and Bucholz (2013) found that members of an older cohort surveyed in the early 1990's were less likely to seek help for drug and alcohol problems than members of a younger cohort surveyed in the early 2000 's. The older adults in the current study may be part of the older, more reluctant cohort. Qualitative research with adults over age 80 has suggested that help-seeking behavior may change because of shifting expectations about health in old-old age. In particular, if changes in abilities or health are attributed to normal aging, then individuals may not seek help for those problems (Elias \& Lowton, 2014). Old-old adults may also not seek help because of a desire to preserve independence in remaining areas of competence (Elias \& Lowton, 2014).

In general, participants in this study were reluctant to ask for help, even if they could not solve the puzzles. On average, they asked for help between 2 and 3 times and solved fewer than 2 puzzles over 15 minutes. Smaller hints were more frequently requested (e.g., the position of 
one piece in the puzzle or a "check" of whether the pieces put together were correct or not) than larger hints (i.e., the position of two pieces or the whole solution). These findings are consistent with the findings of Alea and Cunningham (2003), who examined older adults completing an inductive reasoning task and found that they requested less help than younger adults.

I took the opportunity to assess self-reported past help-seeking behavior, specifically for for mental health problems. I included these items because I thought they might be correlated with the attitudinal and in-session measures of help-seeking behavior. Over half of participants in this study reported that they had sought help for a mental health problem in their lifetime. This rate was higher than suggested by some previous research (Byers et al., 2012; Westerhof et al., 2008). One interesting finding in the current study was that seeking help from a mental health professional (lifetime) was related to WSHS and ATSPPH scores, but seeking help for a mental health problem from any other professional was not. The characteristics of individuals seeking help from mental health professionals may be different from those who do not. Fox, Blank, Rovnyak, \& Barnett (2001) found that rural individuals did not seek mental health care because of difficulties with accessibility. Individuals with better attitudes towards seeking help, especially for mental health problems, may be more likely to overcome barriers to seek out mental health-specific professionals (e.g., psychologists, psychiatrists, etc.). Those who seek help from other professionals (e.g., general practitioners, nurses, clergy), may find these professionals easier to access, without requiring much extra effort to receive services for problems such as sleep, anxiety, or depression. This is why mental health services integrated into primary care may be the best way to connect otherwise reluctant or difficult-to-reach patients to services (Bartels et al., 2004; Rybarczyk et al., 2013). More active help-seeking may result in connection with mental health-specific providers without this step. 
There were several other findings of interest. The association between the PNR, in particular the negative reciprocity subscale, and the MRNI-SF was positive. In other words, individuals with greater endorsement of traditional beliefs about masculine behavior also endorsed a stronger belief in "pay-back" or retribution. The NHM was negatively correlated with the MRNI-SF. In other words, individuals with more traditional beliefs about masculine behavior were less likely to report that they were natural helpers. Although preliminary, it is interesting to consider how negative reciprocity and propensity to be a helper might fit, or not fit, into traditional masculine behavior. For example, recruiting men into nursing professions has proven to be difficult because of the association of the profession with caring (Cottingham, 2013). This caring may be incompatible with a traditional male role. Concerning negative reciprocity, one study found that revenge was more highly associated with aggression for men than for women, and may partially explain sex differences in aggression (Wilkowski, Hartung, Crowe, \& Chai, 2012). These results are consistent with the current study insofar as traditional beliefs about masculine behavior were associated with "natural helping" and negative reciprocity. However, the current study did not find significant sex differences for these variables.

The correlation between the PNR and WSHS was negative, indicating that individuals with a stronger belief in reciprocity had more negative attitudes about seeking help for general problems. This was not an anticipated result. However, reflecting previous research, individuals with strong beliefs in reciprocity might have more negative attitudes about help-seeking if they believe that they will not be able to reciprocate (Greenberg \& Shapiro, 1971; Nadler, 1987). Alternatively, the negative correlation between PNR and WSHS could reflect their relation to traditional beliefs about masculine behavior. 
There were moderate correlations between depressive symptom scores (CES-D) and perceived helpfulness, which were negative for the control group and positive for the experimental group. Individuals in the control group who were more depressed felt less helpful, but individuals in the experimental group who were more depressed felt more helpful. One possible interpretation is that individuals who are more depressed are more pessimistic or realistic about how helpful they are. If the experimental manipulation resulted in any difference in feelings of helpfulness, this difference may be evident among participants who are more depressed. Only 11 participants scored over the clinical cut-off of 16 on the CES-D, 8 in the experimental group and 3 in the control group. Although it appears that that depressed individuals in the experimental group felt more helpful than depressed individuals in the control group, among participants over the CES-D cut-off the difference in perceived helpfulness did not reach statistical significance, $t(1,9)=-2.14, \mathrm{p}=.061$, likely because of inadequate power. Although it would be interesting to know if Hypothesis 1 was supported in depressed participants, because of the very small size of this sub-sample, the main analyses cannot be rerun in this group.

The correlation between the CES-D and OPS subscale was large and negative for male participants, but very small for female participants. Although the sample sizes are small, this could suggest that, among men, depression is more highly related to whether participants reported that they would ask for help or use alternative strategies to solve problems. Somewhat counterintuitively, men who reported more depressive symptoms were less likely to say that they would ask for help or use alternative strategies. These findings are consistent with previous summaries of help-seeking attitudes and behavior in men with depression (Möller-Leimkühler, 
2002). The implication is clinicians may have to take extra steps to engage men who are depressed in treatment and to work with them on flexible problem-solving.

Finally, one of the only significant sex differences in the current study was the finding that women solved significantly more puzzles than men. Age, MoCA score, and number of times help was requested were very similar between men and women and do not explain this difference. However, one possible explanation is that men and women differed on level of education. Nearly $21 \%$ of men in the sample reported high school as their highest level of education, compared to only $6.25 \%$ of women. Women in the current study appear more likely than men to have above a high school education, especially a graduate degree, but the difference was not statistically significant.

\section{Limitations}

The major limitation of the current study was that that the manipulation designed to increase reciprocity did not result in differences in subjective helpfulness in the experimental group compared to the control group. The lack of difference in perceived helpfulness limited my ability to test the norm of reciprocity as a way to increase help-seeking behavior. This study highlighted some of the challenges inherent in doing any study targeting help-seeking behavior and reciprocity. Nonetheless, interesting findings regarding age, adherence to traditional beliefs about masculine behavior, and help-seeking attitudes were obtained. The fact that subjective helpfulness was positively associated with self-reported willingness to seek help (WSHS) hints that the current hypothesis may be able to be adequately tested with slightly different methods. In other words, changing perceived helpfulness may change willingness to seek help. 
The current results may not generalize to all older adults. The current sample was comprised of mostly adults in age 60 to 69. These older adults are referred to as "young-old," may be described as Baby Boomers, and probably do not represent the range of experiences of all older adults. This sample was also highly educated, on average, and over $30 \%$ of participants were still working full time. Racial diversity was minimal. However, researchers traveled to participant's homes, which were often in rural locations and allowed older adults with limited mobility or other disabilities to participate. Care was taken to recruit male participants such that men were adequately represented in the study.

An additional limit to generalizability is that older adults who choose to participate in psychological research may have unique characteristics that make them different from other older individuals. It seems feasible that these middle- and old-old adults exhibit high levels of independence, curiosity, and determination, which could inhibit help-seeking behavior on a puzzle task. These characteristics could also point to a survivor effect. The middle-old and oldold adults who are willing and able to participate in psychological research may be quite different from other similarly-aged adults who are unwilling or unable to participate, or who have died. Among other effects, self-selection of participants may have resulted in older adults in both groups feeling that they were helpful to the experimenter.

Other variables potentially related to help-seeking behavior were not included in the current study. Seeking and accepting help is a complex process (Allen \& Wiles, 2013). Although reciprocity may be part of some decisions about whether or not to seek help, it is far from the only factor (Allen \& Wiles, 2013). For example, self-efficacy, subjective beliefs about the importance of the task, and subjective norms about help-seeking for the task were not measured (Wu et al., 2014). The open-ended questions included in the debriefing of the current study 
suggested that many participants did not want to ask for help, regardless of the difficulty of the task or other factors. Research using both quantitative and qualitative methods has provided some additional insight (Sierra Hernandez et al., 2014; Mackenzie et al., 2008). Qualitative research conducted in New Zealand found that older adults may feel that receiving help is only acceptable in times of very serious need (Allen \& Wiles, 2013). Or, help-seeking behavior may only seem appropriate within the context of close lifelong relations, such as with children or nieces (Allen \& Wiles, 2013). The help-seeking behavior and helper-receiver relationship in the current study was one-time, time-limited, and the puzzle task may not have been important enough to the participant.

The design of the current study required that participants explicitly request help. Although I paid attention to body language and verbal behavior other than direct requests for help, there were no other consistent, obvious choices for coding and recording. In some cases, it appeared the participant was struggling, but we followed our protocol and waited until he or she articulated a request for help. Past studies have used offered verses not offered (but available) help as an experimental conditions in the study (Gross et al., 1979). I conceptualized explicit verbal help-seeking behavior as representative of the type of help-seeking necessary in medical or mental health contexts. However, in other contexts, especially among family and friends, informal or indirect bids for help may be effective (Begum et al., 2012). As a result, help-seeking behavior may have been underestimated in the present study because we did not respond to social cues that may signify a request for help. Future studies could operationalize help-seeking in a broader way, offer help as part of the procedure, or use other manipulations to increase helpseeking such as manipulating the meaning of seeking help or perceived norms about seeking help. 


\section{Summary and Future Directions}

The current study examined one way to increase help-seeking behavior among older adults. In particular, I sought to test the use of reciprocity to increase help-seeking behavior. Studying reciprocity may have implications for how helping professionals approach, build rapport, and treat older adult clients. In the current study, one group of participants was given the opportunity to help the experimenter. The hypothesis was that the group that helped the experimenter would ask for more help on a standardized puzzle task. However, this study could not provide support for the hypothesis because the participant groups did not vary in how helpful

they felt toward the experimenter. Future research should use different ways to induce feelings of helpfulness in research participants, including those in clinical settings. One important consideration seems to be how helpful participants feel they are just by participating in research. In the future, procedures should be developed that would result in differential subjective helpfulness between experimental and control conditions.

This study sought to validate self-report measures of help-seeking attitudes by comparing them to actual in-session help-seeking behavior. In-session help-seeking behavior and self-report measures of attitudes towards help-seeking were not significantly related, suggesting that participants' behavior was not consistent with their self-reported attitudes or that different constructs were measured. However, this study supported the relation between traditional beliefs about masculine behavior and help-seeking attitudes, above and beyond gender identity or sex. Although men are often considered to be reluctant to seek help, there was actually no overall difference by sex. Instead, researchers and clinicians should consider traditional beliefs about masculine behavior as a factor in help-seeking propensity for both men and women. Future 
studies could focus on ways to make seeking help more appealing for individuals who endorse these traditional beliefs.

One unanticipated finding of this study was that older participants asked for less help, even though they also demonstrated lower cognitive ability and performed more poorly on the tangram task. This finding may have implications for professionals working with individuals in older age. Professionals should be aware that, counter-intuitively, older adults with lower cognitive abilities may ask for less help compared to older adults with intact cognitive skills. Encouragingly, over half of the older adults who participated in this study had sought help for a mental health problem or from a mental health professional in their lifetime. Research to examine what factors influence help-seeking behavior for mental health problems is ongoing.

In the future, I am interested in continuing to explore reciprocity as a tool to increase help-seeking behavior among older adults in medical and mental health care settings. Older adults are particularly at risk for feeling like a burden to those around them. If brief research participation provides a way for older adults feel helpful, perhaps it could be a mutually beneficial intervention. Older adults identified as potentially benefitting from mental health services could be randomly assigned to complete a brief survey or data collection procedure (opportunity to give help) and then offered a referral (opportunity to accept help). The outcome of interest could be acceptance of the referral and subsequent participation in a mental health appointment. An alternative manipulation could be to emphasize how the older adult will help a psychology trainee with her or his training by participating in the mental health appointment. As hinted by the current study, I would be careful to assess for depressive symptoms and consider the role of depression in activating reciprocity and help-seeking. 
I am also interested in addressing traditional beliefs about masculine behavior (e.g., not sharing feelings) as a potentially avenue for increasing help-seeking for mental health, physical health, social support, and functional disabilities. Although multiple studies have demonstrated an association between masculine ideologies and attitudes toward seeking help, I am not aware of any published studies that describe a manipulation of traditional beliefs related to masculine behavior in order to facilitate help-seeking behavior. It seems that a "gender role conflict group" for individuals who struggle with issues related to masculine role norms could potentially be helpful. The goal would be to educate masculine individuals about how their gender role beliefs limit their behavior and to open them up to alternative emotional and behavioral possibilities. It would be interesting to measure attitudes and help-seeking behavior before and after an intervention like this in order to evaluate its impact.

Although the current study was not able to demonstrate that invoking reciprocity increased help-seeking behavior or improved attitudes toward help-seeking, it resulted in several other interesting findings and questions for future study. 


\section{References}

Administration on Aging. (2010). Older population by age group: 1900 to 2050 with chart of the $60+$ population. Retrieved from http://www.aoa.gov/AoARoot/Aging_Statistics/future_growth/future_growth.aspx\#age

Adams-Price, C., \& Morse, L. W. (2009). Dependency stereotypes and aging: The implications for getting and giving help in later life. Journal of Applied Social Psychology, 39, 29672984. doi:10.1111/j.1559-1816.2009.00557.x

Alea, N., \& Cunningham, W. R. (2003). Compensatory help-seeking in young and older adults: Does seeking help, help? Experimental Aging Research, 29, 437-456. doi:10.1080/03610730303701

Allen, R. E., \& Wiles, J. L. (2013). Receiving support when older: What makes It OK?. The Gerontologist. doi:10.1093/geront/gnt047.

Angst, J., Ernst, C., (1990). Geschlechtsunterschiede in der psychiatrie. In: Weibliche identität im Wandel. Studium Generale, Wintersemester 1989/ 90. Ruprecht-Karls-Universität, Heidelberg, 69-84.

Antonucci, T. C., Fuhrer, R., \& Jackson, J. S. (1990). Social support and reciprocity: A crossethnic and cross-national perspective. Journal of Social and Personal Relationships, 7(4), 519-530. doi:10.1177/0265407590074008

Ajzen, I., \& Fishbein, M. (1973). Attitudinal and normative variables as predictors of specific behavior. Journal of Personality and Social Psychology, 27, 41-57.

Baldridge, D. C., \& Swift, M. L. (2013). Withholding requests for disability accommodation: The role of individual differences and disability attributes. Journal of Management, 39, 743-762. doi:10.1177/0149206310396375 
Bamonti, P., Price, E. C., \& Fiske, A. (2014). Depressive symptoms and suicide risk in older adults: Value placed on autonomy as a moderator for men but not women. Suicide and Life-Threatening Behavior, 44, 188 - 199. doi: 10.1111/sltb.12062

Bartels, S. J., Coakley, E. H., Zubritsky, C., Ware, J. H., Miles, K. M., Areán, P. A., ... \& Levkoff, S. E. (2004). Improving access to geriatric mental health services: a randomized trial comparing treatment engagement with integrated versus enhanced referral care for depression, anxiety, and at-risk alcohol use. American Journal of Psychiatry, 161(8), 1455-1462. doi:10.1176/appi.ajp.161.8.1455

Begum, A., Whitley, R., Banerjee, S., Matthews, D., Stewart, R., \& Morgan, C. (2012). Helpseeking response to subjective memory complaints in older adults: Toward a conceptual model. The Gerontologist, 53, 462-473. doi:10.1093/geront/gns083

Berger, J. L., Addis, M. E., Green, J. D., Mackowiak, C., \& Goldberg, V. (2013). Men’s reactions to mental health labels, forms of help-seeking, and sources of help-seeking advice. Psychology of Men \& Masculinity, 14, 433-443. doi: 10.1037/a0030175

Berger, J. M., Levant, R., McMillan, K. K., Kelleher, W., \& Sellers, A. (2005). Impact of gender role conflict, traditional masculinity ideology, alexithymia, and age on men's attitudes toward psychological help seeking. Psychology of Men \& Masculinity, 6, 73-78. doi:10.1037/1524-9220.6.1.73

Boerner, K., Brennan, M., Horowitz, A., \& Reinhardt, J. P. (2010). Tackling vision-related disability in old age: An application of the life-span theory of control to narrative data. The Journals of Gerontology: Series B: Psychological Sciences and Social Sciences, 65B, 22-31. doi:10.1093/geronb/gbp098 
Brown, J., \& Chen, S.. (2008). Help-seeking patterns of older spousal caregivers of older adults with dementia. Issues in Mental Health Nursing, 29, 839-852.

doi:10.1080/01612840802182854

Burger, J. M., Sanchez, J., Imberi, J. E., \& Grande, L. R. (2009). The norm of reciprocity as an internalized social norm: Returning favors even when no one finds out. Social Influence, 4, 11-17. doi:10.1080/15534510802131004

Butler, B. E. (1994). Spatial puzzles: A guide for researchers. Canadian Psychology/Psychologie Canadienne, 35, 47-65. doi:10.1037/0708-5591.35.1.47

Byers, A. L., Arean, P. A., \& Yaffe, K. (2012). Low use of mental health services among older Americans with mood and anxiety disorders. Psychiatric Services, 63, 66-72. doi:10.1176/appi.ps.201100121

Calasanti, T. (2004). Feminist gerontology and old men. The Journals of Gerontology: Series B: Psychological Sciences and Social Sciences, 59B, S305-S314.

Conner, K. O., Copeland, V. C., Grote, N. K., Koeske, G., Rosen, D., Reynolds III, C. F., \& Brown, C. (2010). Mental health treatment seeking among older adults with depression: the impact of stigma and race. The American Journal of Geriatric Psychiatry, 18, 531543. doi:10.1097/JGP.0b013e3181cc0366

Castro, M. A. (1974). Reactions to receiving aid as a function of cost to donor and opportunity to aid. Journal of Applied Social Psychology, 4, 194-209. doi:10.1111/j.15591816.1974.tb02640.x

Chipperfield, J. G., Perry, R. P., Bailis, D. S., Ruthig, J. C., \& Loring, P. C. (2007). Gender differences in use of primary and secondary control strategies in older adults with major health problem. Psychology \& Health, 22, 83-105. doi:10.1080/14768320500537563 
Christensen, H., Leach, L. S., Barney, L., Mackinnon, A. J., \& Griffiths, K. M. (2006). The effect of web based depression interventions on self reported help seeking: Randomised controlled trial [ISRCTN77824516]. BMC Psychiatry, 6, 342-349. doi:10.1186/1471244X-6-13

Cialdini, R. B. (1993). Influence: Science and practice, $3^{\text {rd }}$ ed. New York, NY: Harper Collins College Publishers.

Cialdini, R. B., Vincent, J. E., Lewis, S. K., Catalan, J., Wheeler, D., \& Darby, B. L. (1975). Reciprocal concessions procedure for inducing compliance: The door-in-the-face technique. Journal of Personality and Social Psychology, 31, 206-215. doi: $10.1037 / \mathrm{h} 0076284$

Cohen, B. (1999). Measuring the willingness to seek help. Journal of Social Service Research, 26, 67-82. doi:10.1300/J079v26n01_04

Cornally, N., \& McCarthy, G. (2011). Help-seeking behaviour for the treatment of chronic pain. British Journal of Community Nursing, 16, 206 - 217. doi:10.1016/j.pmn.2010.12.006

Corney, R. H. (1990). Sex differences in general practice attendance and help seeking for minor illness. Journal of Psychosomatic Research, 34, 525-534. doi:10.1016/00223999(90)90027-2

Cottingham, M. D. (2014). Recruiting men, constructing manhood how health care organizations mobilize masculinities as nursing recruitment strategy. Gender \& Society, 28, 133-156. doi: 10.1177/0891243213509005

Crawford, J. R., \& Henry, J. D. (2004). The positive and negative affect schedule (PANAS): Construct validity, measurement properties and normative data in a large non-clinical 
sample. British Journal of Clinical Psychology, 43, 245-265.

doi:10.1348/0144665031752934

De Paulo, B. M., \& Fisher, J. D. (1980). The costs of asking for help. Basic and Applied Social Psychology, 1, 23-35. doi: 10.1207/s15324834basp0101_3

Domino, G. (1980). Chinese tangrams as a technique to assess creativity. The Journal of Creative Behavior, 14, 204-213

Drapeau, A., Boyer, R., \& Lesage, A. (2009). The influence of social anchorage on the gender difference in the use of mental health services. The Journal of Behavioral Health Services \& Research, 36, 372-384. doi:10.1007/s11414-009-9168-0

Elias, T., \& Lowton, K. (2014). Do those over 80 years of age seek more or less medical help? A qualitative study of health and illness beliefs and behaviour of the oldest old. Sociology of Health \& Illness, 1-16. doi: 10.1111/1467-9566.12129

Fabrega, H., Mezzich, J., Ulrich, R., \& Benjamin, L. (1990). Females and males in an intake psychiatric setting. Psychiatry: Interpersonal and Biological Processes, 53(1), 1-16.

Faul, F., Erdfelder, E., Lang, A. G., \& Buchner, A. (2007). G*Power 3: A flexible statistical power analysis program for the social, behavioral, and biomedical sciences. Behavior Research Methods, 39, 175-191. doi: 10.3758/BF03193146

Fiori, K., Consedine, N., \& Magai, C. (2008). The adaptive and maladaptive faces of dependency in later life: Links to physical and psychological health outcomes. Aging \& Mental Health, 12, 700-712. doi:10.1080/13607860802148863

Fischer, E. H., \& Farina, A. (1995). Attitudes toward seeking professional psychological help: A shortened form and considerations for research. Journal of College Student Development, $36,368-373$. 
Fiske, A., Bamonti, P. M., Nadorff, M. R., Petts, R. A., \& Sperry, J. A. (2013). Control strategies and suicidal ideation in older primary care patients with functional limitations. The International Journal of Psychiatry in Medicine, 46, 271-289. doi: 10.2190/PM.46.3.c

Fiske, A., Wetherell, J. L., \& Gatz, M. (2009). Depression in older adults. Annual Review of Clinical Psychology, 5, 363-389. doi:10.1146/annurev.clinpsy.032408.153621

Freund, A. M., \& Baltes, P. B. (2002). Life-management strategies of selection, optimization and compensation: Measurement by self-report and construct validity. Journal of Personality and Social Psychology, 82, 642-662. doi:10.1037/0022-3514.82.4.642

Federal Interagency Forum on Aging-Related Statistics. (2012). Older Americans 2012: Key indicators of well-being. Retrieved from http://agingstats.gov/Agingstatsdotnet/Main_Site/Default.aspx

Gatz, M., Johansson, B., Pedersen, N., \& Berg, S. (1993). A cross-national self-report measure of depressive symptomatology. International Psychogeriatrics, 5, 147-156. doi:10.1017/S1041610293001486

Gleason, M. E. J., Iida, M., Shrout, P. E., \& Bolger, N. (2008). Receiving support as a mixed blessing: Evidence for dual effects of support on psychological outcomes. Journal of Personality and Social Psychology, 94, 824-838. doi:10.1037/0022-3514.94.5.824

Gouldner, A. (1960). The norm of reciprocity - a preliminary statement. American Sociological Review, 25, 161-178. doi:10.2307/2092623

Greenberg, M. S., \& Shapiro, S. P. (1971). Indebtedness: An adverse aspect of asking for and receiving help. Sociometry, 34, 290-301. doi:10.2307/2786418 
Gross, A. E., Wallston, B. S., \& Piliavin, I. M. (1979). Reactance, attribution, equity, and the help recipient. Journal of Applied Social Psychology, 9, 297-313. doi:10.1111/j.15591816.1979.tb00804.X

Gulliver, A., Griffiths, K. M., Christensen, H., \& Brewer, J. L. (2012). A systematic review of help-seeking interventions for depression, anxiety and general psychological distress. BMC Psychiatry, 12(81), 1-12. doi:10.1186/1471-244X-12-81

Gupta, R., Duff, M. C., \& Tranel, D. (2011). Bilateral amygdala damage impairs the acquisition and use of common ground in social interaction. Neuropsychology, 25, 137-146. doi:10.1037/a0021123

Hadas, A., \& Midlarsky, E. (2000). Perceptions of responsibility and mental health help-seeking among psychologically distressed older adults. Journal of Clinical Geropsychology, 6(3), 175-185. doi:10.1023/A:1009537031872

Hammer, J. H., Vogel, D. L., \& Heimerdinger-Edwards, S. R. (2013). Men's help seeking: Examination of differences across community size, education, and income. Psychology of Men \& Masculinity, 14, 65-75, doi: 10.1037/a0026813.

Haynes, T. L., Heckhausen, J., Chipperfield, J. G., Perry, R. P., \& Newall, N. E. (2009). Primary and secondary control strategies: Implications for health and well-being among older adults. Journal of Social and Clinical Psychology, 28, 165-197. doi:10.1521/jscp.2009.28.2.165

Haynes, S. N. \& O’Brien, W. H. (2000). Principles and practice of behavioral assessment. New York: Kluwer Academic/Plenum.

Heckhausen, J., Schulz, R., \& Wrosch, C. (1998). Developmental regulation in adulthood: Optimization in Primary and Secondary Control — a multiscale questionnaire (OPS- 
Scales). Unpublished Technical Report, Max Planck Institute for Human Development and Education, Berlin, Germany.

Heckhausen, J., Wrosch, C., \& Schulz, R. (2010). A motivational theory of life-span development. Psychological Review, 117, 32-60. doi:10.1037/a0017668

Hurt, C. S., Burns, A., Brown, R. G., \& Barrowclough, C. (2011). Why don't older adults with subjective memory complaints seek help?. International Journal of Geriatric Psychiatry, 27(4), 394-400. doi: 10.1002/gps.2731

Ingersoll-Dayton, B., \& Antonucci, T. C. (1988). Reciprocal and nonreciprocal social support: Contrasting sides of intimate relationships. Journal of Gerontology: Social Sciences, 43(3), S65-S73. doi:10.1093/geronj/43.3.S65

Jorm, A. F., Griffiths, K. M., Christensen, H., Korten, A. E., Parslow, R. A., \& Rodgers, B. (2003). Providing information about the effectiveness of treatment options to depressed people in the community: A randomized controlled trial of effects on mental health literacy, help-seeking and symptoms. Psychological Medicine, 33, 1071-1079. doi:10.1017/S0033291703008079

Kercher, K. (1992). Assessing subjective well-being in the old-old: The PANAS as a measure of orthogonal dimensions of positive and negative affect. Research on Aging, 14, 131168. doi:10.1177/0164027592142001

Keyes, C. L. M. (2002). The exchange of emotional support with age and its relationship with emotional well-being by age. The Journals of Gerontology: Series B: Psychological Sciences and Social Sciences, 57B, 518-525. doi:10.1093/geronb/57.6.P518

Lee, F. (2002). The social costs of seeking help. Journal of Applied Behavioral Science, 38, 17-35. doi:10.1177/0021886302381002 
Levant, R. F., Hall, R. J., \& Rankin, T. J. (2013). Male role norms Inventory-short form (MRNISF): Development, confirmatory factor analytic investigation of structure, and measurement invariance across gender. Journal of Counseling Psychology, 60, 228-238. doi:10.1037/a0031545

Levant, R. F., Rankin, T. J., Williams, C. M., Hasan, N. T., \& Smalley, K. B. (2010). Evaluation of the factor structure and construct validity of scores on the male role norms InventoryRevised (MRNI-R). Psychology of Men \& Masculinity, 11, 25-37. doi:10.1037/a0017637

Levin, P. F., \& Isen, A. M. (1975). Further studies on the effect of feeling good on helping. Sociometry, 38, 141-147.

Li, T., Fok, H. K., \& Fung, H. H. (2011). Is reciprocity always beneficial? age differences in the association between support balance and life satisfaction. Aging \& Mental Health, 15, 541-547. doi:10.1080/13607863.2010.551340

Mackenzie, C. S., Gekoski, W. L., \& Knox, V. J. (2006). Age, gender, and the underutilization of mental health services: The influence of help-seeking attitudes. Aging \& Mental Health, 10, 574-582. doi: 10.1080/13607860600641200

Mackenzie, C. S., Pagura, J., \& Sareen, J. (2010). Correlates of perceived need for and use of mental health services by older adults in the collaborative psychiatric epidemiology surveys. The American Journal of Geriatric Psychiatry, 18, 1103-1115. doi:10.1097/JGP.0b013e3181dd1c06

Mackenzie, C. S., Scott, T., Mather, A., \& Sareen, J. (2008). Older adults' help-seeking attitudes and treatment beliefs concerning mental health problems. The American Journal of Geriatric Psychiatry, 16, 1010-1019. doi:10.1097/JGP.0b013e31818cd3be 
Mackinnon, A., Jorm, A. F., Christensen, H., Korten, A. E., Jacomb, P. A., \& Rodgers, B. (1999). A short form of the positive and negative affect schedule: Evaluation of factorial validity and invariance across demographic variables in a community sample. Personality and Individual Differences, 27, 405-416. doi:10.1016/S0191-8869(98)00251-7

Maercker, A., Enzler, A., Grimm, G., Helfenstein, E., \& Ehlert, U. (2005). Psychotherapy service utilization and psychotherapy motivation in a representative community sample of the elderly - results of the Zurich older age study. Psychotherapie Psychosomatik Medizinische Psychologie, 55, 177-182. doi:10.1055/s-2004-828510

Magovcevic, M., \& Addis, M.E., (2008). The masculine depression scale: Development and psychometric evaluation. Psychology of Men \& Masculinity, 9(3), 117-132. doi: $10.1037 / 1524-9220.9 .3 .117$

Mansfield, A. K., Addis, M. E., \& Mahalik, J. R. (2003). 'Why won't he go to the doctor?': The psychology of men's help seeking. International Journal of Men's Health, 2, 93-109. doi: $10.3149 /$ jmh.0202.93

Martini, T. S., Grusec, J. E., \& Bernardini, S. C. (2003). Perceptions of help given to healthy older mothers by adult daughters: Ways of initiating help and types of help given. The International Journal of Aging \& Human Development, 57, 237-257. doi:10.2190/WXQ7-XPP8-F0H7-Q2KR

Matejkowski, J., McCarthy, K. S., \& Draine, J. (2011). The personal norm of reciprocity among mental health service users: Conceptual development and measurement. Psychiatric Rehabilitation Journal, 34, 202-213. doi:10.2975/34.3.2011.202.213

Milne, J. (2000). The impact of information on health behaviors of older adults with urinary incontinence. Clinical nursing research, 9, 161-176. 
Möller-Leimkühler, A. M. (2002). Barriers to help-seeking by men: A review of sociocultural and clinical literature with particular reference to depression. Journal of Affective Disorders, 71, 1-9. doi:10.1016/S0165-0327(01)00379-2

McPherson, C. J., Wilson, K. G., Chyurlia, L., \& Leclerc, C. (2010). The balance of give and take in caregiver-partner relationships: An examination of self-perceived burden, relationship equity, and quality of life from the perspective of care recipients following stroke. Rehabilitation Psychology, 55, 194-203. doi:10.1037/a0019359

Meisner, B. A. (2012). A meta-analysis of positive and negative age stereotype priming effects on behavior among older adults. The Journals of Gerontology: Series B: Psychological Sciences and Social Sciences, 67B, 13-17. doi:10.1093/geronb/gbr062

Moreira Jr, E. D., Glasser, D. B., \& Gingell, C. (2005). Sexual activity, sexual dysfunction and associated help-seeking behaviours in middle-aged and older adults in Spain: a population survey. World Journal of Urology, 23, 422-429.

Nadler, A. (1986). Help seeking as a cultural phenomenon: Differences between city and kibbutz dwellers. Journal of Personality and Social Psychology, 51, 976-982. doi:10.1037/0022-3514.51.5.976

Nadler, A. (1987). Determinants of help seeking behaviour: The effects of helper's similarity, task centrality and recipient's self esteem. European Journal of Social Psychology, 17, 57-67. doi:10.1002/ejsp.2420170106

Nadler, A. (1991). Help-seeking behavior: Psychological costs and instrumental benefits. In M. S. Clark (Ed.), Prosocial behavior: Review of personality and social psychology, volume 12 (pp. $290-311)$. Thousand Oaks, CA: Sage. 
Nadler, A., Maler, S., \& Friedman, A. (1984). Effects of helper's sex, subjects' androgyny, and self-evaluation on males' and females' willingness to seek and receive help. Sex Roles, 10, 327-339. doi:10.1007/BF00287550

Nadler, A., Mayseless, O., Peri, N., \& Chemerinski, A. (1985). Effects of opportunity to reciprocate and self-esteem on help-seeking behavior. Journal of Personality, 53, 2335. doi:10.1111/j.1467-6494.1985.tb00886.x

Nagurney, A. J., Reich, J. W., \& Newsom, J. (2004). Gender moderates the effects of independence and dependence desires during the social support process. Psychology and aging, 19, 215-218. doi: 10.1037/0882-7974.19.1.215

Nasreddine Z. S., Phillips N. A., Bédirian V., Charbonneau S., Whitehead V., Collin I., Cummings J.L., Chertkow H. (2005). The Montreal Cognitive Assessment (MoCAC): A brief screening tool for mild cognitive impairment. Journal of the American Geriatric Society, 53, 695-699. doi: 10.1111/j.1532-5415.2005.53221.x

Nisbett, R. E., Wilson, T. D. (1977). Telling more than we can know: Verbal reports on mental processes. Psychological Review, 84, 231 - 259. doi: 10.1037/0033-295X.84.3.231

O’Riley, A. A., \& Fiske, A. (2012). Emphasis on autonomy and propensity for suicidal behavior in younger and older adults. Suicide and Life-Threatening Behavior, 42, 394-404. doi:10.1111/j.1943-278X.2012.00098.x

Pepin, R., Segal, D. L., \& Coolidge, F. L. (2009). Intrinsic and extrinsic barriers to mental health care among community-dwelling younger and older adults. Aging \& Mental Health, 13, 769-777. doi:10.1080/13607860902918231

Pérez-Zepeda, M. U., Arango-Lopera, V. E., Wagner, F. A., Gallo, J. J., Sánchez-García, S., Juárez-Cedillo, T., \& García-Peña, C. (2013). Factors associated with help-seeking 
behaviors in Mexican older individuals with depressive symptoms: a cross-sectional study. International journal of geriatric psychiatry, 28, 1260-1269, doi: 10.1002/gps.3953.

Perugini, M., Gallucci, M., Presaghi, F., \& Ercolani, A. P. (2003). The personal norm of reciprocity. European Journal of Personality, 17(4), 251-283. doi:10.1002/per.474

Pitman, A., \& Osborn, D. P. J. (2011). Cross-cultural attitudes to help seeking among individuals who are suicidal: New perspective for policy-makers. The British Journal of Psychiatry, 199, 8-10. doi:10.1192/bjp.bp.110.087817

Polk, D. M. (2011). Evaluating fairness: Critical assessment of equity theory. In D. Chadee (Ed.), Theories in social psychology (pp. 163-190). United Kingdom: Wiley-Blackwell.

Préville, M., Mechakra Tahiri, S. D., Vasiliadis, H. M., Quesnel, L., Gontijo-Guerra, S., Lamoureux-Lamarche, C., \& Berbiche, D. (2015). Association between perceived social stigma against mental disorders and use of health services for psychological distress symptoms in the older adult population: validity of the STIG scale. Aging \& Mental Health, 19, 464-474.

Price, E. C., Fiske, A., \& Edelstein, B., (2015). Psychosocial interventions for men over 55: A critical review. In press.

Proctor, E. K., Hasche, L., Morrow-Howell, N., Shumway, M., \& Snell, G. (2008). Perceptions about competing psychosocial problems and treatment priorities among older adults with depression. Psychiatric Services, 59, 670-675. doi:10.1176/appi.ps.59.6.670

Radloff, L. S. (1977). The CES-D scale: A self-report depression scale for research in the general population. Applied Psychological Measurement, 1, 385-401.

doi:10.1177/014662167700100306 
Read, R.C. (1965). Tangrams: 330 puzzles. Dover Publications, Inc.: New York, NY.

Rickwood, D., \& Thomas, K. (2012). Conceptual measurement framework for help-seeking for mental health problems. Psychology Research and Behavior Management, 5, 173-183. http://dx.doi.org/10.2147\%2FPRBM.S38707

Robb, C., Haley, W. E., Becker, M. A., Polivka, L. A., \& Chwa, H. (2003). Attitudes towards mental health care in younger and older adults: Similarities and differences. Aging \& Mental Health, 7, 142-152. doi:10.1080/1360786031000072321

Rokke, P. D., Tomhave, J. A., \& Jocic, Z. (1999). The role of client choice and target selection in self-management therapy for depression in older adults. Psychology and Aging, 14, 155-169. doi:10.1037/0882-7974.14.1.155

Rook, K. S. (1987). Reciprocity of social exchange and social satisfaction among older women. Journal of Personality and Social Psychology, 52, 145-154. doi:10.1037/00223514.52 .1 .145

Rosen, J., Rogers, J. C., Marin, R. S., Mulsant, B. H., Shahar, A., \& Reynolds, C. F. (1997). Control-relevant intervention in the treatment of minor and major depression in a longterm care facility. The American Journal of Geriatric Psychiatry, 5, 247-257. doi:10.1097/00019442-199700530-00009

Rybarczyk, B. D., \& Auerbach, S. M. (1990). Reminiscence interviews as stress management interventions for older patients undergoing surgery. The Gerontologist, 30, 522-528. doi:10.1093/geront/30.4.522

Rybarczyk, B., Garroway, A. M., Auerbach, S. M., Rodríguez, V. M., Lord, B. \& Sadock, E. (2013) Primary care psychology: An opportunity for closing the gap in mental health services for older adults, Clinical Gerontologist, 36, 195-215, doi: 
$10.1080 / 07317115.2013 .767870$

Sacco, P., Kuerbis, A., Goge, N., \& Bucholz, K. K. (2013). Help seeking for drug and alcohol problems among adults age 50 and older: A comparison of the NLAES and NESARC surveys. Drug and Alcohol Dependence, 131, 157-161, doi:

10.1016/j.drugalcdep.2012.10.008.

Saunders, G. H., Chisolm, T. H., \& Wallhagen, M. I. (2012). Older adults and hearing helpseeking behaviors. American Journal of Audiology, 21, 331-337. doi:10.1044/10590889(2012/12-0028)

Segal, D. L., Coolidge, F. L., Mincic, M. S., \& O'Riley, A. (2005). Beliefs about mental illness and willingness to seek help: A cross-sectional study. Aging \& Mental Health, 9, 363367. doi: $10.1080 / 13607860500131047$

Shumaker, S. A., \& Jackson, J. S. (1979). The aversive effects of nonreciprocated benefits. Social Psychology Quarterly, 42, 148-158. doi:10.2307/3033695

Sierra Hernandez, C. A., Han, C., Oliffe, J. L., \& Ogrodniczuk, J. S. (2014). Understanding helpseeking among depressed men. Psychology of Men and Masculinity, 15, 345-354. doi: $10.1037 / \mathrm{a} 0034052$

Smith, J. P., Tran, G. Q., \& Thompson, R. D. (2008). Can the theory of planned behavior help explain men's psychological help-seeking? Evidence for a mediation effect and clinical implications. Psychology of Men \& Masculinity, 9, 179-192. doi:10.1037/a0012158

Stahl, J. V., \& Hill, C. E. (2008). A comparison of four methods for assessing natural helping ability. Journal of Community Psychology, 36(3), 289-298. 
Stenzelius, K., Westergren, A., \& Hallberg, I. R. (2007). Bowel function among people 75+ reporting faecal incontinence in relation to help seeking, dependency and quality of life. Journal of Clinical Nursing, 16, 458-468. doi:10.1111/j.1365-2702.2005.01549.x

Strough, J., Cheng, S., \& Swenson, L. M. (2002). Preferences for collaborative and individual everyday problem solving in later adulthood. International Journal of Behavioral Development, 26, 26-35. doi: 10.1080/01650250143000337

Strough, J., McFall, J. P., \& Schuller, K. L. (2010). Endorsement of interpersonal strategies for dealing with hypothetical everyday arthritis problems as a function of marital status, gender, and problem severity. The International Journal of Aging \& Human Development, 70, 39-59. doi:10.2190/AG.70.1.b

Tabachnick, B. G. \& Fidell, L. S. (2013). Using multivariate statistics ( $6^{\text {th }}$ ed.). Upper Saddle River: NJ: Pearson.

Teunissen, D., \& Lagro-Janssen, T. (2004). Urinary incontinence in community dwelling elderly: Are there sex differences in help-seeking behaviour? Scandinavian Journal of Primary Health Care, 22, 209-216. doi:10.1080/02813430410006666

Thompson, E. H., Jr. (2006). Images of old men's masculinity: Still a man? Sex Roles, 55, 633-648. doi:10.1007/s11199-006-9119-7

Thompson, L. W., Coon, D. W., Gallagher-Thompson, D., Sommer, B. R., \& Koin, D. (2001). Comparison of desipramine and cognitive/behavioral therapy in the treatment of elderly outpatients with mild-to-moderate depression. The American Journal of Geriatric Psychiatry, 9, 225-240. doi:10.1176/appi.ajgp.9.3.225 
Thompson, L., Gallagher, D., \& Breckenridge, J. (1987). Comparative effectiveness of psychotherapies for depressed elders. Journal of Consulting and Clinical Psychology, 55, 385-390. doi:10.1037//0022-006X.55.3.385

Uehara, E. S. (1995). Reciprocity reconsidered: Gouldner's 'moral norm of reciprocity' and social support. Journal of Social and Personal Relationships, 12, 483-502. doi:10.1177/0265407595124001

Van Orden, K. A., Witte, T. K., Gordon, K. H., Bender, T. W., \& Joiner, T. E. J. (2008). Suicidal desire and the capability for suicide: Tests of the interpersonal-psychological theory of suicidal behavior among adults. Journal of Consulting and Clinical Psychology, 76, 72-83. doi:10.1037/0022-006X.76.1.72

Wahl, H., Becker, S., Burmedi, D., \& Schilling, O. (2004). The role of primary and secondary control in adaptation to age-related vision loss: A study of older adults with macular degeneration. Psychology and Aging, 19, 235-239. doi:10.1037/0882-7974.19.1.235

Wahl, H., Schilling, O., \& Becker, S. (2007). Age-related macular degeneration and change in psychological control: Role of time since diagnosis and functional ability. The Journals of Gerontology: Series B: Psychological Sciences and Social Sciences, 62B, 90-97. doi:10.1093/geronb/62.2.P90

Weinberger, M. I., Nelson, C. J., \& Roth, A. J. (2011). Self-reported barriers to mental health treatment among men with prostate cancer. Psycho-Oncology, 20, 444-446. doi:10.1002/pon. 1775

Westerhof, G. J., Maessen, M., de Bruijn, R., \& Smets, B. (2008). Intentions to seek (preventive) psychological help among older adults: An application of the theory of planned behaviour. Aging \& Mental Health, 12, 317-322. 
Wilkowski, B. M., Hartung, C. M., Crowe, S. E., \& Chai, C. A. (2012). Men don’t just get mad; they get even: Revenge but not anger mediates gender differences in physical aggression. Journal of Research in Personality, 46, 546-555.

http://dx.doi.org/10.1016/j.jrp.2012.06.001

Wolinsky, F. D., \& Johnson, R. J. (1991). The use of health services by older adults. Journal of Gerontology, 46, 345-357. doi: 10.1093/geronj/46.6.S345

Wu, C., Wang, K., Sun, T., Xu, D., \& Palmer, M. H. (2014). Predicting help $\square$ seeking intention of women with urinary incontinence in Jinan, China: a theory of planned behaviour model. Journal of clinical nursing. doi: 10.1111/jocn.12623

Zauszniewski, J. A. (1996). Self-help and help-seeking behavior patterns in healthy elders. Journal of Holistic Nursing, 14, 223-236. doi: 10.1177/089801019601400305 
Table 1. Descriptive statistics for participant demographics by experimental group and sex

\begin{tabular}{|c|c|c|c|c|c|}
\hline Variable & $\begin{array}{l}\text { Full Sample } \\
n=56\end{array}$ & $\begin{array}{l}\text { Experimental } \\
n=31\end{array}$ & $\begin{array}{l}\text { Control } \\
n=25\end{array}$ & $\begin{array}{l}\text { Male } \\
n=24\end{array}$ & $\begin{array}{l}\text { Female } \\
n=32\end{array}$ \\
\hline $\operatorname{Age}(M, S D)$ & $68.37(7.30)$ & $67.84(7.08)$ & $69.04(7.66)$ & $68.21(5.58)$ & $68.50(8.45)$ \\
\hline Female participant & $32(57.14)$ & $18(58.06)$ & $14(56.00)$ & 0 & $32(100)$ \\
\hline Female experimenter & $32(57.14)$ & $18(58.06)$ & $14(56.00)$ & $13(54.17)$ & $19(59.38)$ \\
\hline Run at WVU & $40(75.47)$ & $21(70.00)$ & $19(82.61)$ & $18(75.00)$ & $22(68.75)$ \\
\hline $\begin{array}{l}\text { Marital Status } \\
\text { Single } \\
\text { Married/Partnered } \\
\text { Separated/Divorced } \\
\text { Widowed }\end{array}$ & $\begin{array}{lr}6 & (10.91) \\
31 & (56.37) \\
11 & (19.00) \\
7 & (12.73)\end{array}$ & $\begin{array}{ll}4 & (12.90) \\
17 & (54.84) \\
7 & (22.58) \\
3 & (9.68)\end{array}$ & $\begin{array}{ll}2 & (8.33) \\
14 & (58.34) \\
4 & (16.67) \\
4 & (16.67)\end{array}$ & $\begin{array}{ll}4 & (16.67) \\
15 & (62.5) \\
4 & (16.67) \\
1 & (4.17)\end{array}$ & $\begin{array}{ll}2 & (6.45) \\
16 & (51.62) \\
7 & (22.58) \\
6 & (19.35)\end{array}$ \\
\hline $\begin{array}{l}\text { Education } \\
\text { GED } \\
\text { High School } \\
\text { Some College } \\
\text { College Degree } \\
\text { Graduate Degree } \\
\text { Other }\end{array}$ & $\begin{array}{ll}4 & (7.14) \\
7 & (12.50) \\
9 & (16.07) \\
17 & (30.36) \\
17 & (30.36) \\
2 & (3.57)\end{array}$ & $\begin{array}{ll}3 & (9.68) \\
5 & (16.13) \\
5 & (16.13) \\
8 & (25.81) \\
9 & (29.03) \\
1 & (3.23)\end{array}$ & $\begin{array}{ll}1 & (4.00) \\
2 & (8.00) \\
4 & (16.00) \\
9 & (36.00) \\
8 & (32.00 \\
1 & (4.00)\end{array}$ & $\begin{array}{ll}2 & (8.33) \\
5 & (20.83) \\
2 & (8.33) \\
8 & (33.33) \\
6 & (25.00) \\
1 & (4.17)\end{array}$ & $\begin{array}{ll}2 & (6.25) \\
2 & (6.25) \\
7 & (21.88) \\
9 & (28.13) \\
11 & (34.38) \\
1 & (3.13)\end{array}$ \\
\hline $\begin{array}{l}\text { Occupation } \\
\text { Working full time } \\
\text { Working part time } \\
\text { Homemaker } \\
\text { Retired } \\
\text { Multiple roles }\end{array}$ & $\begin{array}{ll}17 & (30.36) \\
2 & (3.57) \\
1 & (1.79) \\
32 & (57.14)\end{array}$ & $\begin{array}{ll}8 & (25.81) \\
1 & (3.23) \\
1 & (3.23) \\
20 & (64.52) \\
1 & (3.23)\end{array}$ & $\begin{array}{ll}9 & (36.00) \\
1 & (4.00) \\
0 & \\
12 & (48.00) \\
3 & (12.00)\end{array}$ & $\begin{array}{ll}5 & (20.83) \\
1 & (4.17) \\
0 & \\
16 & (66.67) \\
2 & (8.33)\end{array}$ & $\begin{array}{ll}12 & (37.50) \\
1 & (3.13) \\
1 & (3.13) \\
16 & (50.00) \\
2 & (6.25)\end{array}$ \\
\hline $\begin{array}{l}\text { Size of Hometown } \\
\text { Rural }(<2,500) \\
\text { Small Town } \\
\text { Town/Small City } \\
\text { Large City }(> \\
100,000)\end{array}$ & $\begin{array}{lr}11 & (19.64) \\
12 & (21.43) \\
27 & (48.21) \\
6 & (10.71)\end{array}$ & $\begin{array}{l}6(19.35) \\
8(25.81) \\
12(38.71) \\
5 \quad(16.13)\end{array}$ & $\begin{array}{ll}5 & (20.00) \\
4 & (16.00) \\
16 & (60.00) \\
1 & (4.00)\end{array}$ & $\begin{array}{ll}5 & (20.83) \\
7 & (29.17) \\
11 & (45.83) \\
1 & (4.17)\end{array}$ & $\begin{array}{lr}6 & (18.75) \\
5 & (15.63) \\
16 & (50.00) \\
5 & (19.35)\end{array}$ \\
\hline
\end{tabular}

Note. All numbers are $n(\%)$ unless otherwise indicated. No participants endorsed a primary occupational status of "student," "unemployed - looking for work" or "disabled." Participants with "multiple roles" indicated that they were both retired and disabled, or a homemaker and working part-time. 
Table 2. Descriptive statistics for study variables by group and participant sex.

\begin{tabular}{lllllll}
\hline Variable & Range & $\begin{array}{l}\text { Total } \\
n=56\end{array}$ & $\begin{array}{l}\text { Experimental } \\
n=31\end{array}$ & $\begin{array}{l}\text { Control } \\
n=25\end{array}$ & $\begin{array}{l}\text { Male } \\
n=24\end{array}$ & $\begin{array}{l}\text { Female } \\
n=32\end{array}$ \\
\hline MoCA & $20-30$ & $25.88(2.75)$ & $25.74(2.54)$ & $26.04(3.03)$ & $25.17(2.71)$ & $26.41(2.70)$ \\
$\begin{array}{l}\text { \# of Times } \\
\text { Help Requested } \\
\text { Latency }\end{array}$ & $0-8$ & $2.45(1.94)$ & $2.54(1.65)$ & $2.32(2.29)$ & $2.21(1.67)$ & $2.63(2.14)$ \\
\# Solved & $4-900$ & $384.70(291.78)$ & $338.74(259.74)$ & $441.68(323.51)$ & $406.88(270.35)$ & $368.06(310.09)$ \\
ATSPPH & $8-4$ & $1.89(1.23)$ & $1.84(1.29)$ & $1.96(1.17)$ & $1.5(.98)^{\mathrm{a}}$ & $2.19(1.33)$ \\
WSHS & $44-72$ & $55.31(6.89)$ & $54.94(6.85)$ & $55.76(7.06)$ & $54.55(7.67)$ & $55.88(6.31)$ \\
MRNI-SF & $21-86$ & $64.11(15.11)$ & $64.85(14.19)$ & $63.19(16.44)$ & $68.96(14.57)^{\mathrm{a}}$ & $60.47(14.68)$ \\
CES-D & $0-38$ & $9.61(8.23)$ & $10.91(8.96)$ & $8.02(7.08)$ & $9.88(9.72)$ & $9.42(7.07)$ \\
$\begin{array}{l}\text { Perceived } \\
\text { helpfulness }\end{array}$ & $1-5$ & $3.73(1.26)$ & $3.74(1.03)$ & $3.72(1.51)$ & $3.71(1.37)$ & $3.75(1.19)$ \\
OPS & $18-40$ & $29.80(4.68)$ & $29.48(3.97)$ & $30.20(5.50)$ & $30.13(5.05)$ & $29.56(4.45)$ \\
OPS-Help & $9-20$ & $14.77(14.50)$ & $14.55(2.19)$ & $15.04(2.79)$ & $14.88(2.56)$ & $14.69(2.43)$ \\
PNR & $35-59$ & $45.57(5.98)$ & $45.43(5.36)$ & $45.75(6.79)$ & $47.17(6.22)$ & $44.39(5.60)$ \\
NHM & $5-35$ & $25.15(5.54)$ & $25.77(4.17)$ & $24.38(6.91)$ & $24.43(4.66)$ & $25.68(6.13)$ \\
\hline
\end{tabular}

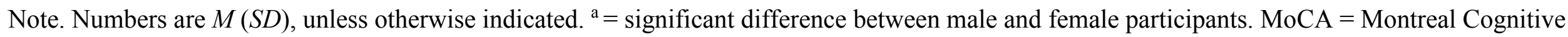
Assessment; \# of Times Help Requested = number of times that participants requested help during the tangram task; Latency (sec's) = latency to seeking help for the first time during the tangram task, in seconds; \# Solved = number of tangram puzzles solved in 15 minutes; ATSPPH = Attitudes Toward Seeking Professional Psychological Help; WSHS = Willingness to Seek Help Scale; MRNI-SF = Masculine Role Norms Inventory, Short Form; CES-D = Centers for Epidemiologic Studies - Depression Scale; Perceived helpfulness (manip. check) = participants' self-reported rating of how helpful they felt, obtained during manipulation check; OPS = Optimization of Primary and Secondary Control Scale - Compensatory Primary Control subscale, OPS-Help = four items from the OPS - Compensatory Primary Control subscale addressing help-seeking; PNR = Personal Norm of Reciprocity scale; $\mathrm{NMH}=$ Natural Helper Measure. 
Table 3. Bivariate correlations among demographic and study variables, full sample $N=56$.

\begin{tabular}{|c|c|c|c|c|c|c|c|c|c|c|c|c|c|}
\hline Measures & 1 & 2 & 3 & 4 & 5 & 6 & 7 & 8 & 9 & 10 & 11 & 12 & 13 \\
\hline 1. Age & - & & & & & & & & & & & & \\
\hline 2. MoCA & $-.38^{*}$ & - & & & & & & & & & & & \\
\hline $\begin{array}{l}\text { 3. \# Help } \\
\text { Requested }\end{array}$ & $-.29 *$ & .23 & - & & & & & & & & & & \\
\hline 4. Latency & $.36^{*}$ & -.11 & $-.69 *$ & - & & & & & & & & & \\
\hline 5. \# Solved & $-.36^{*}$ & $.47^{*}$ & .21 & -.18 & - & & & & & & & & \\
\hline 6. ATSPPH & -.01 & -.24 & .06 & .01 & -.09 & - & & & & & & & \\
\hline 7. WSHS & .00 & -.07 & .03 & -.02 & -.09 & $.41 *$ & - & & & & & & \\
\hline 8. MRNI-SF & .16 & -.15 & -.17 & .03 & -.24 & $-.30 *$ & $-.43^{*}$ & - & & & & & \\
\hline 9. CES-D & .04 & $-.35^{*}$ & -.09 & -.16 & -.17 & .20 & .07 & -.02 & - & & & & \\
\hline $\begin{array}{l}\text { 10. Perceived } \\
\text { helpfulness }\end{array}$ & .15 & -.20 & .03 & -.04 & -.23 & .21 & $.29 *$ & .03 & -.05 & - & & & \\
\hline 11. OPS & .04 & .04 & -.01 & -.01 & .08 & -.12 & .22 & -.22 & $-.38 *$ & $.31 *$ & - & & \\
\hline 12. OPS-Help & .07 & .00 & -.01 & .00 & .08 & -.02 & $.27^{*}$ & -.20 & $-.37 *$ & $.28^{*}$ & $.89 *$ & - & \\
\hline 13. PNR & -.13 & .08 & -.09 & -.18 & -.05 & .04 & $-.35^{*}$ & $.36^{*}$ & .03 & -.14 & -.14 & -.23 & - \\
\hline 14. NHM & -.25 & -.01 & .14 & -.10 & .19 & .13 & .11 & $-.28 *$ & -.09 & .21 & $.28 *$ & .22 & -.03 \\
\hline
\end{tabular}

Note. $*=p<.05$. MoCA $=$ Montreal Cognitive Assessment; \# Help Requested $=$ number of times participant asked for help during the tangram task; Latency = latency to seeking help for the first time during the tangram task; \# Solved = number of tangram puzzles solved in 15 minutes; ATSPPH = 
Attitudes Toward Seeking Professional Psychological Help; WSHS = Willingness to Seek Help Scale; MRNI-SF = Masculine Role Norms Inventory - Short Form; CES-D = Centers for Epidemiologic Studies - Depression Scale; Perceived helpfulness = participants' self-reported rating of how helpful they felt; OPS = Optimization of Primary and Secondary Control Scale - Compensatory Primary Control subscale, OPS-Help = four items from the OPS addressing help-seeking; PNR = Personal Norm of Reciprocity scale; NMH = Natural Helper Measure. 
Table 4. Bivariate correlations among demographic and study variable by experimental group

\begin{tabular}{|c|c|c|c|c|c|c|c|c|c|c|c|c|c|c|}
\hline Measures & 1 & 2 & 3 & 4 & 5 & 6 & 7 & 8 & 9 & 10 & 11 & 12 & 13 & 14 \\
\hline 1. Age & - & -.19 & $-.37 *$ & $.38 *$ & -.20 & -.04 & -.03 & .11 & .23 & .24 & .18 & .13 & -.18 & -.16 \\
\hline 2. MoCA & $-.58 *$ & - & $.35^{*}$ & -.05 & $.42 *$ & -.22 & -.22 & .03 & $-.42 *$ & $-.35 *$ & -.05 & -.15 & .19 & -.36 \\
\hline $\begin{array}{l}\text { 3. \# Help } \\
\text { Requested }\end{array}$ & -.21 & .14 & - & $-.59 *$ & .26 & .00 & -.04 & -.04 & -.21 & -.11 & -.05 & .06 & -.19 & -.04 \\
\hline 4. Latency & .32 & -.19 & $-.76^{*}$ & - & -.02 & -.01 & .04 & -.30 & -.05 & -.31 & -.01 & -.15 & -.02 & -.03 \\
\hline 5. \# Solved & $-.58 *$ & $.52 *$ & .18 & -.38 & - & -.10 & -.21 & -.29 & -.32 & -.31 & -.02 & .04 & -.16 & .13 \\
\hline 6. ATSPPH & .04 & -.25 & .11 & .05 & -.07 & - & $.60 *$ & -.24 & .20 & .19 & -.29 & -.15 & .04 & .03 \\
\hline 7. WSHS & .03 & .06 & .09 & -.10 & .06 & .21 & - & $-.43 *$ & .12 & .25 & .04 & .11 & -.24 & .09 \\
\hline 8. MRNI-SF & .21 & -.31 & -.27 & .33 & -.20 & -.36 & $-.42 *$ & - & .21 & .01 & -.18 & -.13 & $.40 *$ & -.33 \\
\hline 9. CES-D & -.18 & -.26 & .02 & -.24 & .11 & .19 & .02 & -.36 & - & .35 & $-.41 *$ & -.39 & .22 & .03 \\
\hline $\begin{array}{l}\text { 10. Perceived } \\
\text { Helpfulness }\end{array}$ & .08 & -.10 & .12 & .15 & -.17 & .22 & .32 & .05 & $-.50 *$ & - & .30 & .32 & -.06 & .02 \\
\hline 11. OPS & -.08 & .10 & .03 & -.04 & .17 & .03 & .38 & -.25 & -.36 & .31 & - & .88 & -.32 & .07 \\
\hline $\begin{array}{l}\text { 12. OPS- } \\
\text { Help }\end{array}$ & .01 & .11 & -.05 & .09 & .10 & .12 & $.41 *$ & -.23 & -.34 & .26 & $.90 *$ & - & $-.40 *$ & .13 \\
\hline 13. PNR & -.08 & -.02 & -.20 & .33 & .06 & .04 & $-.47 *$ & .32 & -.20 & -.20 & -.02 & -.10 & - & -.18 \\
\hline 14. NHM & -32 & .23 & .23 & -.11 & .26 & .20 & .15 & -.26 & -.27 & .32 & $.42 *$ & .32 & .06 & - \\
\hline
\end{tabular}

Note. Correlations for the experimental group $(n=31)$ are above the diagonal and shaded. Correlations for the control group $(n=26)$ are below the diagonal and unshaded. ${ }^{*}=p \geq .05$. MoCA $=$ Montreal Cognitive Assessment; \# Help Requested = number of times participant asked for help during the tangram task; Latency = latency to seeking help for the first time during the tangram task; \# Solved = number of tangram puzzles solved in 15 
minutes; ATSPPH = Attitudes Toward Seeking Professional Psychological Help; WSHS = Willingness to Seek Help Scale; MRNI-SF = Masculine Role Norms Inventory - Short Form; CES-D = Centers for Epidemiologic Studies - Depression Scale; Perceived helpfulness = participants' selfreported rating of how helpful they felt; OPS = Optimization of Primary and Secondary Control Scale - Compensatory Primary Control subscale, OPS-Help = four items from the OPS addressing help-seeking; PNR = Personal Norm of Reciprocity scale; NMH = Natural Helper Measure. 
Table 5. Bivariate correlations among demographic and study variables by sex

\begin{tabular}{|c|c|c|c|c|c|c|c|c|c|c|c|c|c|c|}
\hline Measures & 1 & 2 & 3 & 4 & 5 & 6 & 7 & 8 & 9 & 10 & 11 & 12 & 13 & 14 \\
\hline 1. Age & - & $-.47 *$ & $-.46^{*}$ & $.51^{*}$ & $-.43 *$ & -.07 & -.08 & $.39^{*}$ & .19 & .17 & -.13 & -.03 & -.07 & -.37 \\
\hline 2. MoCA & -.26 & - & .23 & -.27 & $.39 *$ & -.29 & -.11 & -.12 & $-.42 *$ & -.34 & .02 & .02 & -.05 & -.08 \\
\hline $\begin{array}{l}\text { 3. \# Help } \\
\text { Requested }\end{array}$ & .14 & .18 & - & $-.72 *$ & .14 & .17 & -.15 & -.11 & .06 & .08 & -.02 & -.02 & -.10 & .09 \\
\hline 4. Latency & -.00 & .16 & $-.62 *$ & - & -.27 & .11 & .13 & .16 & 0.23 & .07 & -.19 & -.18 & .16 & -.06 \\
\hline 5. \# Solved & -.22 & $.52 *$ & .31 & .04 & - & -.18 & -.03 & -.30 & -.10 & -.19 & .28 & .26 & -.13 & -.31 \\
\hline 6. ATSPPH & .10 & -.25 & -.11 & -.12 & -.03 & - & $.51^{*}$ & -.25 & -.07 & $.57 *$ & .04 & .09 & -.18 & -.26 \\
\hline 7. WSHS & .15 & -.10 & .25 & -.21 & -.27 & .30 & - & $-.46^{*}$ & .17 & .25 & .16 & .28 & $-.57 *$ & .00 \\
\hline 8. MRNI-SF & -.27 & -.07 & -.21 & -.22 & .03 & -.33 & -.37 & - & -.14 & .03 & -.19 & -.12 & $.37 *$ & -.33 \\
\hline 9. CES-D & -.17 & -.29 & -.27 & -.10 & -.29 & $.44^{*}$ & -.02 & .07 & - & .15 & -.01 & -.06 & -.23 & -.02 \\
\hline $\begin{array}{l}\text { 10. Perceived } \\
\text { Helpfulness }\end{array}$ & .12 & -.07 & -.03 & -.18 & -.34 & -.15 & .32 & -.05 & -.23 & - & .25 & .27 & -.22 & .02 \\
\hline 11. OPS & .37 & .09 & .02 & .23 & -.18 & -.27 & .29 & -.33 & $-.71^{*}$ & .37 & - & .86 & -.01 & .30 \\
\hline $\begin{array}{l}\text { 12. OPS - } \\
\text { Help }\end{array}$ & .27 & -.01 & .01 & .27 & -.20 & -.13 & .26 & -.33 & $-.66^{*}$ & .29 & .93 & - & -.23 & .22 \\
\hline 13. PNR & -.25 & .34 & -.31 & .18 & .24 & .31 & -.10 & .24 & .25 & -.03 & -.30 & -.24 & - & .11 \\
\hline 14. NHM & .06 & .07 & .22 & -.14 & -.18 & -.08 & .26 & -.13 & -.18 & $.47^{*}$ & .27 & .23 & -.19 & - \\
\hline
\end{tabular}


Note. Correlations for female participants $(n=33)$ are above the diagonal and shaded. Correlations for male participants $(n=23)$ are below the diagonal and unshaded; $*=p<.05$. MoCA = Montreal Cognitive Assessment; \# Help Requested = number of times participant asked for help during the tangram task; Latency = latency to seeking help for the first time during the tangram task; \# Solved = number of tangram puzzles solved in 15 minutes; ATSPPH = Attitudes Toward Seeking Professional Psychological Help; WSHS = Willingness to Seek Help Scale; MRNI-SF = Masculine Role Norms Inventory - Short Form; CES-D = Centers for Epidemiologic Studies - Depression Scale; Perceived helpfulness = participants' selfreported rating of how helpful they felt; OPS = Optimization of Primary and Secondary Control Scale - Compensatory Primary Control subscale, OPS-Help = four items from the OPS addressing help-seeking; PNR = Personal Norm of Reciprocity scale; NMH = Natural Helper Measure. 
Appendix A.

Answer key for tangrams.
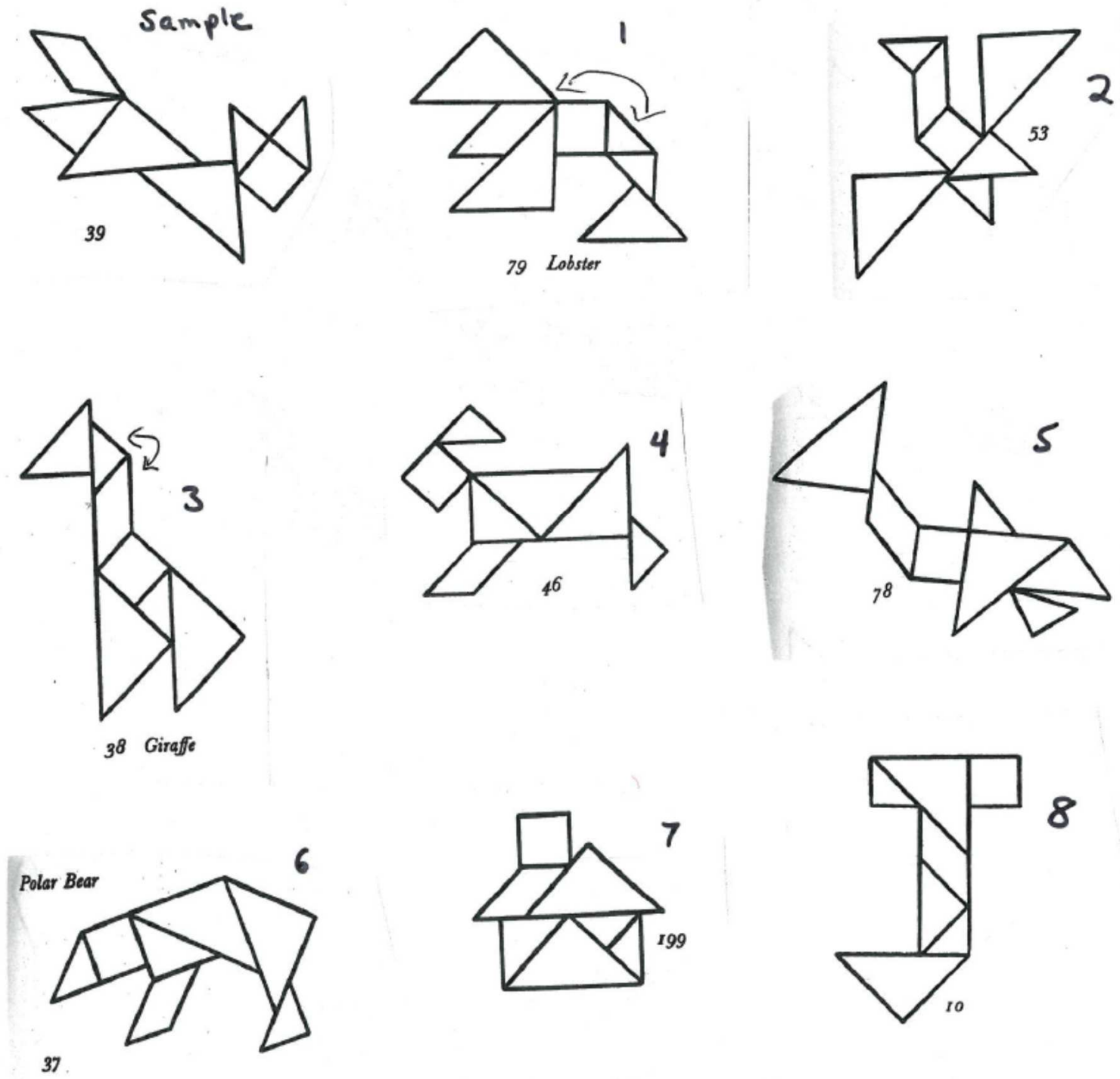
Appendix B.

Indicate to what extent you feel this way right now, that is, at the present moment. Use the following scale to record your answers.

\begin{tabular}{|l|l|l|l|l|l|}
\hline & $\begin{array}{l}\text { 1 } \\
\text { Very Slightly } \\
\text { or Not at All }\end{array}$ & A little & 3 Moderately & 4 \\
Quite a Bit & Extremely \\
\hline 1. Afraid & & & & & \\
\hline 2. Distressed & & & & & \\
\hline 3. Excited & & & & & \\
\hline 4. Upset & & & & & \\
\hline 5. Scared & & & & & \\
\hline 6. Enthusiastic & & & & & \\
\hline 7. Alert & & & & & \\
\hline 8. Inspired & & & & & \\
\hline 9. Nervous & & & & & \\
\hline 10. Determined & & & & & \\
\hline
\end{tabular}


Appendix C.

MONTREAL COGNITIVE ASSESSMENT (MOCA)

Version 7.1 Original Version

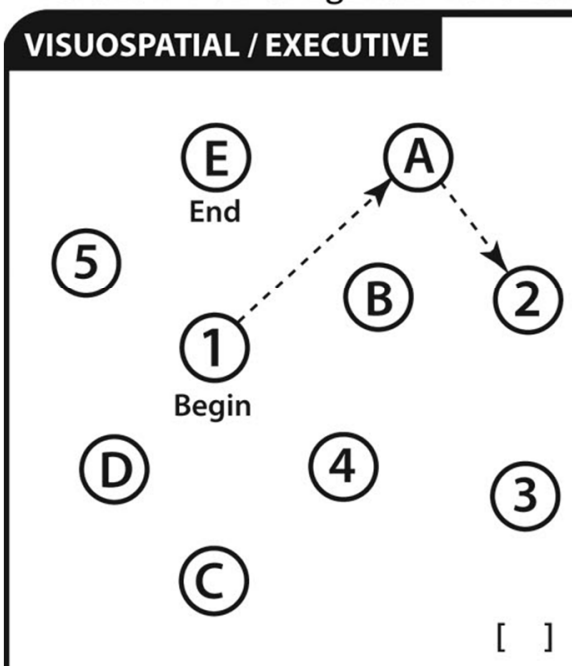

IVMIVIC :

Education: Date of birth :

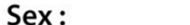
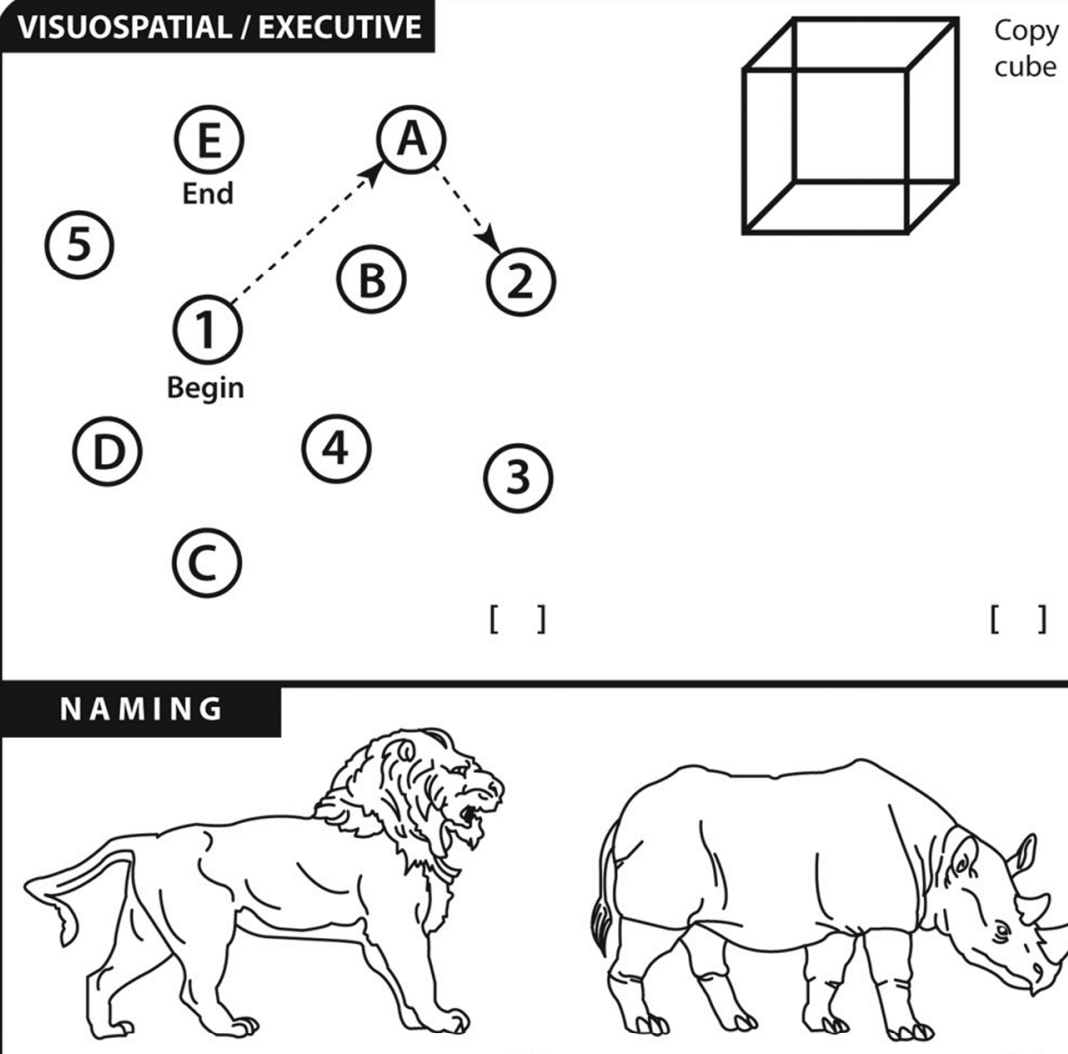

$$
\begin{aligned}
& \text { Draw CLOCK (Ten past eleven) } \\
& \text { ( } 3 \text { points) }
\end{aligned}
$$

\begin{tabular}{|c|c|c|}
\hline $\begin{array}{c}{[\quad]} \\
\text { Contour }\end{array}$ & $\begin{array}{c}{\left[\begin{array}{l}{[} \\
\text { Numbers }\end{array}\right.} \\
\text { Number }\end{array}$ & [ ] ] \\
\hline
\end{tabular}
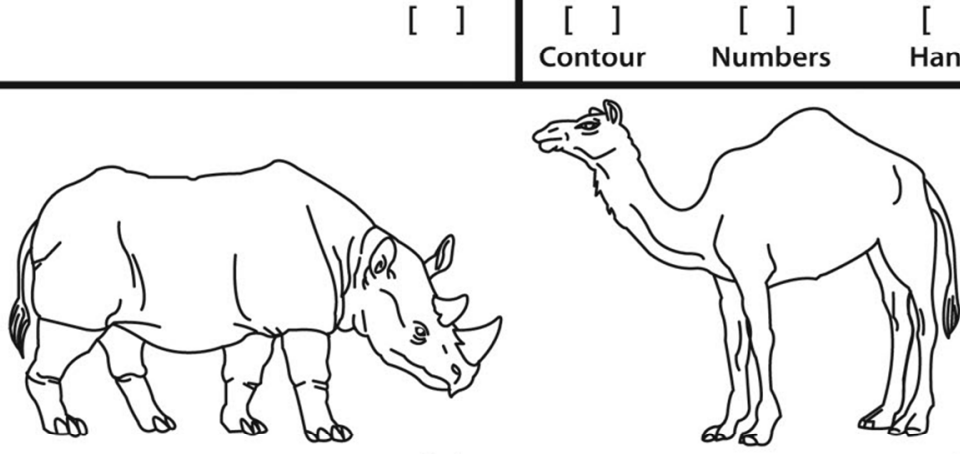

[ ]

[ ]

[ ]

\section{MEM OR Y}

Read list of words, subject must repeat them. Do 2 trials, even if $1 \mathrm{st}$ trial is successful. Do a recall after 5 minutes.

\begin{tabular}{|r|l|l|l|l|l|}
\hline & FACE & VELVET & CHURCH & DAISY & RED \\
\hline 1st trial & & & & & \\
\hline 2nd trial & & & & & \\
\hline
\end{tabular}

\section{ATTENTION}

Read list of digits (1 digit/ sec.).

Subject has to repeat them in the forward order

[ ] $2128 \begin{array}{llll} & 1 & 5 & 4\end{array}$ Subject has to repeat them in the backward order

[ ] 742

Read list of letters. The subject must tap with his hand at each letter $A$. No points if $\geq 2$ errors

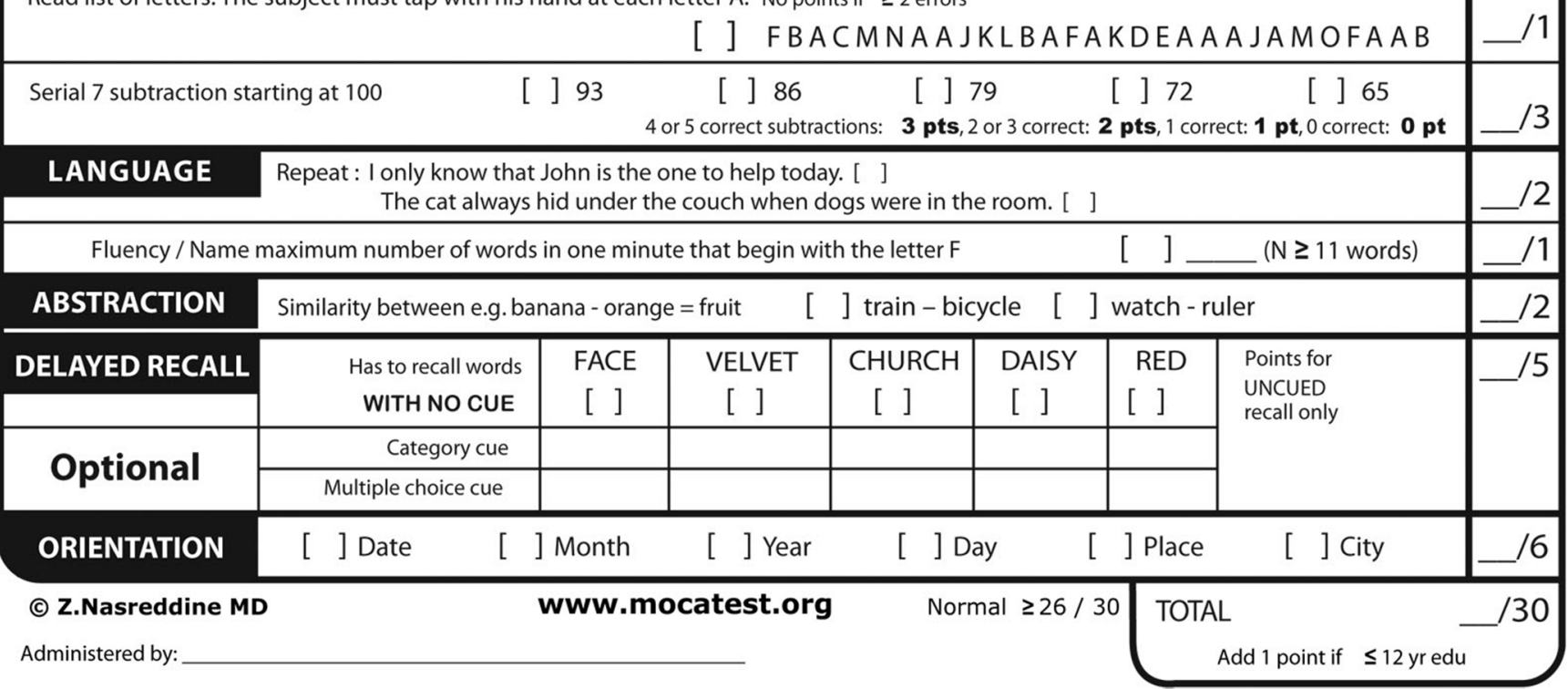




\section{Appendix D.}

Please read each item carefully and place an " $X$ " in the appropriate column.

\begin{tabular}{|c|c|c|c|c|}
\hline & $\begin{array}{l}\text { 0 Strongly } \\
\text { Disagree }\end{array}$ & 1 Disagree & 2 Agree & $\begin{array}{l}3 \text { Strongly } \\
\text { Agree }\end{array}$ \\
\hline $\begin{array}{l}\text { 1. If I were afraid of heights, I would try to conceal this from my } \\
\text { friends. }\end{array}$ & & & & \\
\hline $\begin{array}{l}\text { 2. No conflict in our marriage could be so severe that my partner } \\
\text { and I could not solve it on our own. }\end{array}$ & & & & \\
\hline $\begin{array}{l}\text { 3. Were a problem to develop in my sex life, I would either need } \\
\text { to solve it alone or to live with it, because I would not be able to } \\
\text { discuss it with anyone. }\end{array}$ & & & & \\
\hline $\begin{array}{l}\text { 4. If, for whatever reason, I were to have prolonged difficulty } \\
\text { walking, I would do whatever possible to avoid asking help from } \\
\text { anyone. }\end{array}$ & & & & \\
\hline $\begin{array}{l}\text { 5. When something breaks down in my home, I usually persist in } \\
\text { trying to fix it myself, even when it is difficult and I am wasting } \\
\text { time and money. }\end{array}$ & & & & \\
\hline $\begin{array}{l}\text { 6. If I were suddenly afraid to go out in the street, I believe I } \\
\text { could overcome without help from anyone else. }\end{array}$ & & & & \\
\hline $\begin{array}{l}\text { 7. If a serious problem were to arise in my marriage, I would be } \\
\text { willing to talk about it with a professional, or with a friend or } \\
\text { relative, but in any case I would not keep it to myself. }\end{array}$ & & & & \\
\hline $\begin{array}{l}\text { 8. Sexual problems are a difficult topic to talk about, but if I wer } \\
\text { to have such a problem I would use the services of an expert. }\end{array}$ & & & & \\
\hline $\begin{array}{l}\text { 9. If I ever have difficulty seeing, I will try to arrange my life so } \\
\text { no one will notice. }\end{array}$ & & & & \\
\hline $\begin{array}{l}\text { 10. If I were to lose control and hurt my child in a moment of } \\
\text { anger, I would need to make sure that no one would know about } \\
\text { it. }\end{array}$ & & & & \\
\hline $\begin{array}{l}\text { 11. Discovering unexpectedly that my spouse was hitting my } \\
\text { child too hard would lead me to seek out someone who could } \\
\text { intervene as quickly as possible. }\end{array}$ & & & & \\
\hline $\begin{array}{l}\text { 12. Were my spouse to suggest that we go to a family therapist, I } \\
\text { would take the position that we are able to solve our own } \\
\text { problems. }\end{array}$ & & & & \\
\hline $\begin{array}{l}\text { 13. I believe that a time of mourning for a loved one would be a } \\
\text { time when I would need other people. }\end{array}$ & & & & \\
\hline
\end{tabular}




\begin{tabular}{|c|c|c|c|c|}
\hline & $\begin{array}{l}\text { 0 Strongly } \\
\text { Disagree }\end{array}$ & 1 Disagree & 2 Agree & $\begin{array}{l}3 \text { Strongly } \\
\text { Agree }\end{array}$ \\
\hline $\begin{array}{l}\text { 14. If both my legs were to be broken in an accident, I would } \\
\text { prefer to stay home for a few months rather than be pushed } \\
\text { around in a wheelchair. }\end{array}$ & & & & \\
\hline $\begin{array}{l}\text { 15. Some problems are so distressing that they cannot be } \\
\text { managed alone. }\end{array}$ & & & & \\
\hline $\begin{array}{l}\text { 16. If I were to develop an irrational fear of the dark and I were } \\
\text { concerned that it might affect my child, I would seek out a person } \\
\text { who could help me overcome my fear. }\end{array}$ & & & & \\
\hline $\begin{array}{l}\text { 17. At the funeral of a loved one, I would do all I could do appear } \\
\text { strong and not show any weakness. }\end{array}$ & & & & \\
\hline $\begin{array}{l}\text { 18. If I had a chronic illness, such as diabetes, I would seek out } \\
\text { persons who could offer me guidance in addition to the medical } \\
\text { treatment. }\end{array}$ & & & & \\
\hline $\begin{array}{l}\text { 19. If a member of my family were to become mentally ill, I } \\
\text { would hope for contact with an expert who could advise me in } \\
\text { how I might be of help. }\end{array}$ & & & & \\
\hline $\begin{array}{l}\text { 20. If I thought I had a problem of excessive drinking, I could } \\
\text { discuss it with persons who might be able to help me. }\end{array}$ & & & & \\
\hline $\begin{array}{l}\text { 21. Problems of sexual dysfunction would cause me to seek } \\
\text { outside help. }\end{array}$ & & & & \\
\hline $\begin{array}{l}\text { 22. During a period of bereavement for a loved one, I would } \\
\text { allow friends and relatives to take over some of the tasks for } \\
\text { which I am usually responsible. }\end{array}$ & & & & \\
\hline $\begin{array}{l}\text { 23. Becoming addicted to drugs is the kind of situation that } \\
\text { would cause me to place my fate in the hands of an expert. }\end{array}$ & & & & \\
\hline $\begin{array}{l}\text { 24. If, in the course of medical treatment for a physical ailment, I } \\
\text { were to experience serious anxiety, I would ask the doctor to } \\
\text { treat the anxiety. }\end{array}$ & & & & \\
\hline $\begin{array}{l}\text { 25. If I am ever depressed, I will seek out the appropriate person } \\
\text { to tell about it. }\end{array}$ & & & & \\
\hline
\end{tabular}




\section{Appendix E.}

Below are a number of statements pertaining to psychology and mental health issues. Please read each of the following statements carefully and place an " $\mathrm{X}$ " in the column that indicates your level of agreement.

\begin{tabular}{|c|c|c|c|c|}
\hline & $\begin{array}{l}\mathbf{0} \\
\text { Disagree }\end{array}$ & $\begin{array}{l}1 \text { Partly } \\
\text { Disagree }\end{array}$ & $\begin{array}{l}2 \text { Partly } \\
\text { Agree }\end{array}$ & $\begin{array}{l}3 \\
\text { Agree }\end{array}$ \\
\hline $\begin{array}{l}\text { 1. If I believed I was having a mental breakdown, my first inclination } \\
\text { would be to get professional attention. }\end{array}$ & & & & \\
\hline $\begin{array}{l}\text { 2. The idea of talking about problems with a psychologist strikes me as } \\
\text { a poor way to get rid of emotional conflicts. }\end{array}$ & & & & \\
\hline $\begin{array}{l}\text { 3. If I were experiencing a serious emotional crisis at this point in my } \\
\text { life, I would be confident that I could find relief in psychotherapy. }\end{array}$ & & & & \\
\hline $\begin{array}{l}\text { 4. There is something admirable in the attitude of a person who is } \\
\text { willing to cope with his or her conflicts and fears without resorting to } \\
\text { professional help. }\end{array}$ & & & & \\
\hline $\begin{array}{l}\text { 5. I would want to get psychological help if I were worried or upset for } \\
\text { a long period of time. }\end{array}$ & & & & \\
\hline 6. I might want to have psychological counseling in the future. & & & & \\
\hline $\begin{array}{l}\text { 7. A person with an emotional problem is not likely to solve it alone; he } \\
\text { or she is likely to solve it with professional help. }\end{array}$ & & & & \\
\hline $\begin{array}{l}\text { 8. Considering the time and expense involved in psychotherapy, it } \\
\text { would have doubtful value for a person like me. }\end{array}$ & & & & \\
\hline $\begin{array}{l}\text { 9. A person should work out his or her own problems: getting } \\
\text { psychological counseling would be a last resort. }\end{array}$ & & & & \\
\hline $\begin{array}{l}\text { 10. Personal and emotional troubles, like many things, tend to work out } \\
\text { by themselves. }\end{array}$ & & & & \\
\hline
\end{tabular}




\section{Appendix F.}

Please complete the questionnaire by checking the box which indicates your level of agreement or disagreement with each statement. Give only one answer for each statement.

\begin{tabular}{|c|c|c|c|c|c|c|c|}
\hline & $\begin{array}{l}1 \text { Strongly } \\
\text { Disagree }\end{array}$ & 2 & $\begin{array}{l}3 \\
\text { Disagree } \\
\end{array}$ & $\begin{array}{l}4 \\
\text { Neutral }\end{array}$ & $\begin{array}{l}5 \\
\text { Agree }\end{array}$ & 6 & $\begin{array}{l}7 \text { Strongly } \\
\text { Agree }\end{array}$ \\
\hline $\begin{array}{l}\text { 1. Homosexuals should never } \\
\text { marry. }\end{array}$ & & & & & & & \\
\hline $\begin{array}{l}\text { 2. The President of the U.S. sho } \\
\text { always be a man. }\end{array}$ & & & & & & & \\
\hline $\begin{array}{l}\text { 3. Men should be the leader in } \\
\text { group. }\end{array}$ & & & & & & & \\
\hline $\begin{array}{l}\text { 4. Men should watch football } \\
\text { games instead of soap operas. }\end{array}$ & & & & & & & \\
\hline $\begin{array}{l}\text { 5. All homosexual bars should } \\
\text { closed down. }\end{array}$ & & & & & & & \\
\hline $\begin{array}{l}\text { 6. Men should have home } \\
\text { improvement skills. }\end{array}$ & & & & & & & \\
\hline $\begin{array}{l}\text { 7. Men should be able to fix me } \\
\text { things around the house. }\end{array}$ & & & & & & & \\
\hline $\begin{array}{l}\text { 8. A man should prefer watchin } \\
\text { action movies to reading roman } \\
\text { novels. }\end{array}$ & & & & & & & \\
\hline $\begin{array}{l}\text { 9. Men should always like to ha } \\
\text { sex. }\end{array}$ & & & & & & & \\
\hline $\begin{array}{l}\text { 10. Boys should prefer to play } \\
\text { with trucks rather than dolls. }\end{array}$ & & & & & & & \\
\hline $\begin{array}{l}\text { 11. A man should not turn dow } \\
\text { sex. }\end{array}$ & & & & & & & \\
\hline $\begin{array}{l}\text { 12. A man should always be th } \\
\text { boss. }\end{array}$ & & & & & & & \\
\hline $\begin{array}{l}\text { 13. Homosexuals should never } \\
\text { kiss in public. }\end{array}$ & & & & & & & \\
\hline $\begin{array}{l}\text { 14. A man should know how to } \\
\text { repair his car if it should break } \\
\text { down. }\end{array}$ & & & & & & & \\
\hline $\begin{array}{l}\text { 15. A man should never admit } \\
\text { when others hurt his feelings. }\end{array}$ & & & & & & & \\
\hline
\end{tabular}




\begin{tabular}{|c|c|c|c|c|c|c|c|}
\hline & $\begin{array}{l}1 \text { Strongly } \\
\text { Disagree }\end{array}$ & 2 & $\begin{array}{l}3 \\
\text { Disagree }\end{array}$ & $\begin{array}{l}4 \\
\text { Neutral }\end{array}$ & $\begin{array}{l}5 \\
\text { Agree }\end{array}$ & 6 & $\begin{array}{l}7 \text { Strongly } \\
\text { Agree }\end{array}$ \\
\hline $\begin{array}{l}\text { 16. Men should be detached in } \\
\text { emotionally charged situations. }\end{array}$ & & & & & & & \\
\hline $\begin{array}{l}\text { 17. It is important for a man to } \\
\text { take risks, even if he might get } \\
\text { hurt. }\end{array}$ & & & & & & & \\
\hline $\begin{array}{l}\text { 18. A man should always be ready } \\
\text { for sex. }\end{array}$ & & & & & & & \\
\hline $\begin{array}{l}\text { 19. When the going gets tough, } \\
\text { men should get tough. }\end{array}$ & & & & & & & \\
\hline $\begin{array}{l}20 \text {. I think a young man should try } \\
\text { to be physically tough, even if he's } \\
\text { not big. }\end{array}$ & & & & & & & \\
\hline $\begin{array}{l}\text { 21. Men should not be too quick to } \\
\text { tell others that they care about } \\
\text { them. }\end{array}$ & & & & & & & \\
\hline
\end{tabular}


Appendix G.

Below is a list of the ways you might have felt or behaved. Please check the boxes to tell me how often you have felt this way in the past week or so.

\begin{tabular}{|c|c|c|c|c|}
\hline DURING THE PAST WEEK: & $\begin{array}{l}\text { Rarely or } \\
\text { Not at All } \\
\end{array}$ & $\begin{array}{l}\text { Some of the } \\
\text { Time }\end{array}$ & Occasionally & $\begin{array}{l}\text { Most of the } \\
\text { Time }\end{array}$ \\
\hline \multicolumn{5}{|c|}{$\begin{array}{l}\text { 1. I was bothered by things that don't usually } \\
\text { bother me. }\end{array}$} \\
\hline \multicolumn{5}{|c|}{ 2. I did not feel like eating, my appetite was poor. } \\
\hline \multicolumn{5}{|c|}{$\begin{array}{l}\text { 3. I felt that I could not shake the blues even with } \\
\text { the help from my family and friends. }\end{array}$} \\
\hline \multicolumn{5}{|c|}{ 4. I felt that I was just as good as other people. } \\
\hline \multicolumn{5}{|c|}{$\begin{array}{l}\text { 5. I had trouble keeping my mind on what I was } \\
\text { doing. }\end{array}$} \\
\hline \multicolumn{5}{|l|}{ 6. I felt depressed. } \\
\hline \multicolumn{5}{|c|}{ 7. I felt that everything I did was an effort. } \\
\hline \multicolumn{5}{|l|}{ 8. I felt hopeful about the future. } \\
\hline \multicolumn{5}{|c|}{ 9. I thought my life had been a failure. } \\
\hline \multicolumn{5}{|l|}{ 10. I felt fearful. } \\
\hline \multicolumn{5}{|l|}{ 11. My sleep was restless. } \\
\hline \multicolumn{5}{|l|}{ 12. I was happy. } \\
\hline \multicolumn{5}{|l|}{ 13. I talked less than usual. } \\
\hline \multicolumn{5}{|l|}{ 14. I felt lonely. } \\
\hline \multicolumn{5}{|l|}{ 15. People were unfriendly. } \\
\hline \multicolumn{5}{|l|}{ 16. I enjoyed life. } \\
\hline \multicolumn{5}{|l|}{ 17. I had crying spells. } \\
\hline \multicolumn{5}{|l|}{ 18. I felt sad. } \\
\hline \multicolumn{5}{|l|}{ 19. I felt that people dislike me. } \\
\hline 20. I could not "get going". & & & & \\
\hline
\end{tabular}


Appendix H.

For the following set of questions, please read each one carefully and decide how much it applies to you. Indicate whether the statement is never true, seldom true, sometimes true, often true or almost always true.

1. When I get stuck on a task, I don't hesitate asking others for advice.

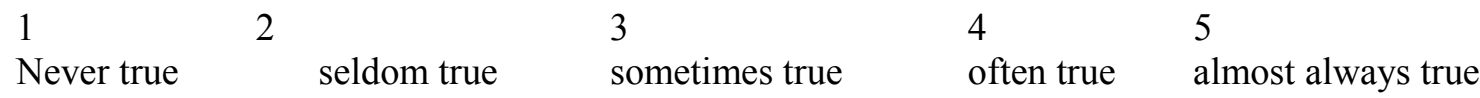

2. When I cannot get to a goal directly, I sometimes choose a roundabout way to achieve it.

$\begin{array}{lllll}1 & 2 & 3 & 4 & 5 \\ \text { Never true } & \text { seldom true } & \text { sometimes true } & \text { often true } & \text { almost always true }\end{array}$

3. When I can no longer make progress on something, I look for new ways to reach my goal.

$\begin{array}{lllll}1 & 2 & 3 & 4 & 5 \\ \text { Never true } & \text { seldom true } & \text { sometimes true } & \text { often true } & \text { almost always true }\end{array}$

4. When I cannot solve a problem by myself I ask others for help.

$\begin{array}{lllll}1 & 2 & 3 & 4 & 5 \\ \text { Never true } & \text { seldom true } & \text { sometimes true } & \text { often true } & \text { almost always true }\end{array}$

5. When obstacles get in my way, I find another way to get what I want.

$\begin{array}{lllll}1 & 2 & 3 & 4 & 5 \\ \text { Never true } & \text { seldom true } & \text { sometimes true } & \text { often true } & \text { almost always true }\end{array}$

6. When difficulties become too great, I ask others for advice.

$\begin{array}{lllll}1 & 2 & 3 & 4 & 5 \\ \text { Never true } & \text { seldom true } & \text { sometimes true } & \text { often true } & \text { almost always true }\end{array}$

7. When obstacles get in my way, I try to think of other ways of reaching my goal, even if they are unusual.

$\begin{array}{lllll}1 & 2 & 3 & 4 & 5 \\ \text { Never true } & \text { seldom true } & \text { sometimes true } & \text { often true } & \text { almost always true }\end{array}$

8. When obstacles get in my way, I try to get help from others.

$\begin{array}{lllll}1 & 2 & 3 & 4 & 5 \\ \text { Never true } & \text { seldom true } & \text { sometimes true } & \text { often true } & \text { almost always true }\end{array}$




\section{Appendix I.}

Please read the following statements carefully and put an " $\mathrm{X}$ " in the appropriate box.

\begin{tabular}{|c|c|c|c|c|c|c|c|}
\hline & $\begin{array}{l}1 \text { Strongly } \\
\text { Disagree }\end{array}$ & 2 & $\begin{array}{l}3 \\
\text { Disagree }\end{array}$ & $\begin{array}{l}4 \\
\text { Neutral }\end{array}$ & $\begin{array}{l}5 \\
\text { Agree }\end{array}$ & 6 & $\begin{array}{l}7 \text { Strongly } \\
\text { Agree }\end{array}$ \\
\hline $\begin{array}{l}\text { 1. If someone does a favor for me, } \\
\text { I am ready to return it. }\end{array}$ & & & & & & & \\
\hline $\begin{array}{l}\text { 2. When someone does me a favor, } \\
\text { I feel committed to repay him/her. }\end{array}$ & & & & & & & \\
\hline $\begin{array}{l}\text { 3. If someone lends me money as a } \\
\text { favor, I feel I should give him/her } \\
\text { back something more than what is } \\
\text { strictly due. }\end{array}$ & & & & & & & \\
\hline $\begin{array}{l}\text { 4. I go out of my way to help } \\
\text { somebody who has been kind to } \\
\text { me before. }\end{array}$ & & & & & & & \\
\hline $\begin{array}{l}5 . \text { I am kind and nice if others } \\
\text { behave well with me, otherwise } \\
\text { it's tit-for-tat. }\end{array}$ & & & & & & & \\
\hline $\begin{array}{l}\text { 6. If somebody offends me, I will } \\
\text { offend him/her back. }\end{array}$ & & & & & & & \\
\hline $\begin{array}{l}\text { 7. If somebody is impolite to me, I } \\
\text { become impolite. }\end{array}$ & & & & & & & \\
\hline $\begin{array}{l}\text { 8. The way I treat others depends } \\
\text { much on how they treat me }\end{array}$ & & & & & & & \\
\hline $\begin{array}{l}\text { 9. To help somebody is the best } \\
\text { policy to be certain that } \mathrm{s} / \text { he will } \\
\text { help you } \\
\text { in the future. }\end{array}$ & & & & & & & \\
\hline $\begin{array}{l}\text { 10. I do not behave badly with } \\
\text { others so as to avoid them } \\
\text { behaving badly with me. }\end{array}$ & & & & & & & \\
\hline $\begin{array}{l}\text { 11. I fear the reactions of a person } \\
\text { I have previously treated badly. }\end{array}$ & & & & & & & \\
\hline $\begin{array}{l}\text { 12. When I pay someone } \\
\text { compliments, I expect that } \mathrm{s} / \mathrm{he} \text { in } \\
\text { turn will reciprocate. }\end{array}$ & & & & & & & \\
\hline
\end{tabular}


Appendix J.

Please rate your level of agreement with the following items.

1. I often find myself helping others with their problems.

1 2 3

4 5

6

7

Never

Always

2. I have been told that I am good at helping others.

1 2 3

4 5

6

7

Never

Always

3. I have been told that I would be a good counselor/therapist.

1 2 3

4 5

6

7

Never

Always

4. I consider myself to be "naturally" good at helping others.

1

2

3

4

5

6

7

Never

Always

5. I am comfortable helping others with their problems.

1

2

3

4

5

6

7

Never

Always 
Appendix K.

\section{. 1. Have you ever sought help from a mental health professional?}

Examples of a mental health professional are counselor, therapist, psychologist, psychiatrist, or clinical social worker.

Yes $\quad$ No

2. Have you ever sought help for a mental health problem from any professional, including your regular doctor, nurse, or clergy?

Examples of mental health problems are depression, anxiety, "nerves," stress, sleep problems, memory problems, anger, and relationship problems.

Yes No

The final set of questions asks for information that will be used to interpret our results. Results will be reported only by group, and not for individual respondents. Your answers are anonymous and cannot be linked to you individually.

1. What is your age?

2. What is your sex?
a. Male
b. Female

3. Which racial or ethnic group describes you best? (please choose one)
a. White or Caucasian, not Hispanic
b. Black or African-American
c. Hispanic or Latino/Latina
d. American Indian/Native American or Native Alaskan
e. Asian or Pacific Islander
f. Other or multi-racial

4. What is your marital status?
a. Single
b. Married
c. Long-term partner
d. Separated
e. Divorced
f. Widowed

5. In what city and state do you currently live?

6. What city and state would you consider your hometown?

7. How would you describe your hometown? (please choose one)

a. $\operatorname{Rural}(2,500$ or fewer residents)

b. Small town (more than 2,500 but fewer than 20,000)

c. Town/small city $(20,000-100,000$ resident $)$ 
d. Large city (more than 100,000 residents)

8. What is your highest level of education?
a. GED
b. High School
c. Some College
d. College Degree
e. Graduate Degree or other training post-college
f. Other

9. What is your current job or occupation status? (please choose one)
a. Working full time
b. Working part time
c. Homemaker
d. Student
e. Unemployed - looking for work
f. Retired
g. Disabled - unable to work 


\section{Appendix L.}

\section{"Problem-Solving in Adults Over 60" Procedure}

I. Recruitment will take place as described in the protocol. The researcher will contact the potential participant via phone or the participant will call and leave a message on a secure voicemail.

Participants will complete a brief screening process over the phone. They will be asked if they can (1) read and (2) see and use their hands well enough to complete a puzzle. The researcher will schedule the experimental session at a time that is convenient for the participant. The participant may choose to come to the Life Sciences Building or to have the experiment take place in their home. An address will be obtained in order to mail a parking pass to the participant or locate their home.

II. Once arrived at the experimental session, the informed consent process will take place. The experimenter will review the consent form with the participant. The participant will be given time to read the consent form and ask the experimenter any questions. Participants will also be offered a copy of the consent form for their records. If a participant chooses not to sign the consent form, the session will be terminated. The participant will be told that the study is regarding "problem-solving in adults age 60 and over." The entire session should take approximately 90 minutes. The session will be audiotaped for quality control purposes. The recordings will not be transcribed but will be used to ensure accurate completion of the procedures by research assistants. In some cases, we will use the recordings to review participant's verbal responses to the questions. The participant may decline to be audiotaped and will sign a separate line to indicate their willingness to be audiotaped. The audio recordings will be deleted as soon as possible after they are reviewed, usually within less than one month. At this time, with permission of the participant, the experimenter will turn on the voice recorder and leave it running for the rest of the session.

III. Half of the participants will be randomly assigned to give help. The participants assigned to give help will be asked the following question:

(Help) Before we get started, I wonder if I can ask you a favor. As you know, I'm looking for people age 60 and over for my research. You probably have a better idea than I do about how to engage people in that group. How do you think I could find older adults and get them to participate in my study?

The following prompts may also be used:

Where do you think I could find people?

What made you decide to participate?

Where do you go during the day?

If the participant refuses to help, this will be noted and the procedure will continue with the Tangrams.

For individuals who are randomly assigned to the control group, they will be asked

(Control) Would you please describe your living room to me? Give as much detail as you can. 
The following prompts may be used in either condition:

Please, go on.

Anything else you can think of?

In both conditions, the participant will be prompted to speak for approximately $1-1.5$ minutes.

If the participant finishes speaking after 1 minute or continues beyond 1.5 minutes, the researcher will say

(Help) That's great, wonderful. Thank you so much, this is such a big help. It's really going to help me finish my project on time, which is important to help me graduate! Now we have to move on.

(Control) Ok, we have to move on.

IV. The participant will be asked to complete the PANAS (first measure in survey packet).

V. The tangrams will be introduced.

Tangrams are 7-piece puzzles that can be combined in many different ways, to make many different forms like animals or people (show example). (show pieces) There are two large triangles, one medium triangle, two small triangles, a square, and a parallelogram that make up each figure. The trick is to look at an outline of the whole puzzle and figure out how all of the pieces fit to make that shape. Here's how you would do this one (demonstrate). Now I'm going to mix these up and let you have a try just for practice (allow participant to re-create shape). (If they cannot solve after about 1 minutes) Let me show you again. (demonstrate again, then move on). Do you have any questions?

The participant will be provided with instructions and a "help menu" to suggest the types of help that they may receive. This help menu is adapted from Alea \& Cunningham (2003). It will also allow the experimenter to code and provide the appropriate hint for each question in a way that is identical across participants. The instructions and help menu will be explained as follows

You'll have 15 minutes to complete as many puzzles as you can. These are hard, so just do your best. You can only move on to the next one if you complete the one you are working on correctly. Let me know when you are done with each one by saying "DONE." You may ask me for help. Here are the different types of help you can ask for. You may ask for the position of one piece of your choice in the puzzle, two pieces of your choice in the puzzle, ask me to check whether you have put 3 or more pieces together correctly, or to give you the whole solution. These are the only types of help you can ask for. So, for this puzzle, (demonstrate with pieces) you could ask where this piece goes, where these two pieces go, if three or more pieces you put together are right, or if you're really stumped, you can ask for the answer and then we'll move on. You can ask for help on any puzzle and ask for help as many times as you want.

If the participant has difficulty solving the sample task, the experimenter may show him/her the correct answer a $2^{\text {nd }}$ time. The participant will also be provided with written instructions and help menu visible throughout the task. The instructions state 


\section{Instructions}

You will have 15 minutes to complete as many puzzles as you can.

You can only move on if you solve a puzzle correctly.

Let me know when you are finished with each one by saying "DONE."

You may ask for help on any puzzle.

You may ask for help as many times as necessary.

Help Menu

1. Hint-One piece

2. Hint - Two pieces

3. Check ("Is that right?" for 3 or more pieces)

\section{Solution}

Participants will be provided with up to 8 puzzles ( 15 minutes of the task). The experimenter will be seated behind and to the side of the participant, immediately available to help but not in direct sight. Procedural questions such as "do I have all the pieces for this puzzle?" may be answered and will be noted. The experimenter will also ask participants to clarify which type of help they are asking for (on the help menu) if it is unclear ("which type of help would you like?"), but ONLY after it is clear that the participant has requested help. The experimenter will not suggest or remind the participant to ask for help while they are working on a puzzle. After participants complete one puzzle, the experimenter will provide the next puzzle.

If the participant does not ask for help on the first puzzle, upon beginning the second puzzle the experimenter will say

Remember, you can ask for help.

In order to encourage the participants during this difficult task:

If/when the participant solves a puzzle correctly, the experimenter will say

That's correct, good job

If the participant cannot solve the puzzle but asks for the answer in order to complete a puzzle

[after giving the solution] These are hard, just keep doing your best.

The participant will be warned when 2 minutes are left for the puzzles.

After 15 minutes has elapsed, the task will be discontinued. All participants will be told

You were very persistent. 
VI. The MoCA (attached) will be administered as an indication of cognitive functioning. However, all participants will continue with the procedure.

VII. Then, the participant will be provided with the packet of questionnaires and asked to complete them. This should take approximately 30 minutes.

VIII. After the questionnaires are completed, the participant will take part in a verbal manipulation check and funnel debriefing. I will record their answers to the following questions.

We've done a lot of different things today. What did you think this study was about?

When you answered my question about [how to recruit older adults/your living room], how much did you feel you were helping me, from 1 (not helping at all) to 5 (helping a lot).

What did you think [the recruitment or living room question/the tangrams/the questionnaire] was about? Why did we do that?

Did you believe you could ask for help on the tangrams?

This study was about a bit more than problem-solving [or insert whatever they thought it was about]. In particular, we were interested in what influences a person to ask for help on a difficult problem. There were actually two groups in this study. One group was asked to help the experimenter and the other was not. You were randomly assigned to be in the [helping/not helping] group. There is some research that suggests that people like to make things fair so if I help you, you might be more likely to help me in the future. We were interested to see if giving people the opportunity to help might increase their willingness to ask for help. The surveys asked about your attitudes about seeking help and some other variables that we think might be related. What questions do you have? Thank you so much for participating.

All participant questions will be answered.

At this time, the participant will receive payment and be asked to sign the payment receipt.

Finally, the participant will be offered a form where they can indicate their interest in participating in other research or to receive a summary of results. 